\title{
"Do labour mobility and technological collaborations foster geographical knowledge diffusion? The case of European regions"
}

Ernest Miguélez and Rosina Moreno 


\title{
${ }_{B}^{\oplus}|| R|E| A \mid$
}

Institut de Recerca en Economia Aplicada Regional i Públic

Research Institute of Applied Economics

WEBSITE: www.ub-irea.com•CONTACT: irea@ub.edu

\section{AQR}

\author{
Grup de Recerca Anàlisi Quantitativa Regional \\ Regional Quantitative Analysis Research Group \\ WEBSITE: www.ub.edu/aqr/•CONTACT: aqr@ub.edu
}

\section{Universitat de Barcelona}

Av. Diagonal, $690 \cdot 08034$ Barcelona

The Research Institute of Applied Economics (IREA) in Barcelona was founded in 2005, as a research institute in applied economics. Three consolidated research groups make up the institute: AQR, RISK and GiM, and a large number of members are involved in the Institute. IREA focuses on four priority lines of investigation: (i) the quantitative study of regional and urban economic activity and analysis of regional and local economic policies, (ii) study of public economic activity in markets, particularly in the fields of empirical evaluation of privatization, the regulation and competition in the markets of public services using state of industrial economy, (iii) risk analysis in finance and insurance, and (iv) the development of micro and macro econometrics applied for the analysis of economic activity, particularly for quantitative evaluation of public policies.

IREA Working Papers often represent preliminary work and are circulated to encourage discussion. Citation of such a paper should account for its provisional character. For that reason, IREA Working Papers may not be reproduced or distributed without the written consent of the author. A revised version may be available directly from the author.

Any opinions expressed here are those of the author(s) and not those of IREA. Research published in this series may include views on policy, but the institute itself takes no institutional policy positions. 


\title{
Do labour mobility and technological collaborations foster geographical knowledge diffusion? The case of European regions
}

\author{
Ernest Miguélez $^{\ddagger *}$ \& Rosina Moreno ${ }^{\dagger *}$ \\ ${ }^{\ddagger}$ Economics and Statistics Division, WIPO \\ *AQR-IREA \\ ${ }^{\dagger}$ University of Barcelona \\ ernestmiguelez@gmail.com, rmoreno@ub.edu
}

\begin{abstract}
The goal of this paper is twofold: first, we aim to assess the role played by inventors' cross-regional mobility and collaborations in fostering knowledge diffusion across regions and subsequent innovation. Second, we intend to evaluate the feasibility of using mobility and co-patenting information to build cross-regional interaction matrices to be used within the spatial econometrics toolbox. To do so, we depart from a knowledge production function where regional innovation intensity is a function not only of the own regional innovation inputs but also external accessible knowledge stocks gained through interregional interactions. Differently from much of the previous literature, cross-section gravity models of mobility and co-patents are estimated to use the fitted values to build our 'spatial' weights matrices, which characterize the intensity of knowledge interactions across a panel of 269 regions covering most European countries over 6 years.
\end{abstract}

Key words: inventors' spatial mobility, co-patenting, gravity models, weights matrix, knowledge production function

JEL: C8, J61, O31, O33, R0 


\section{Introduction and motivation}

Knowledge diffusion and creation have been core elements not only within the geography of innovation literature in the past two decades, but also within other related streams, such as new growth economics, regional science, or innovation studies. In large part, this relevance lies in the belief that the combination and recombination of previously unconnected ideas lead to new knowledge production, subsequent technological innovations, and ensuing economic growth and well-being (Aghion and Howitt, 1998; Jones, 1995). Further, knowledge diffusion in the form of knowledge spillovers is central to this literature as a cause of endogenous growth (Romer, 1986, 1990). Still, despite the prominent role conferred to knowledge spillovers, measuring the actual channels through which knowledge is transmitted is far from straightforward.

This paper follows this avenue of reasoning, and aims to assess the role played by the geographical mobility of skilled workers and their research collaboration patterns on the dissemination and creation of technical knowledge across a large panel of European regions, using a Knowledge Production Function (KPF hereafter) framework with 'neighbouring' effects. A second contribution of this paper is more methodological. As it is well known in the spatial econometrics literature, one of the main weaknesses within related studies concerns the arbitrary choice of the weights matrix to characterize knowledge interactions across regions. The present inquiry aims to develop a refinement of the typical matrices based on purely geographical definitions precisely exploiting information on this cross-regional mobility of inventors and their collaborative ties. As it is customary assumed in the literature, distance matters so as the interdependences between units are stronger if they are closer in the space (Rincke, 2010). Our tenet in this paper states, however, that distance matters precisely because labour mobility of skills and interpersonal formal ties tend to be regional in nature (Breschi and Lissoni, 2004, 2009; Singh, 2005; Zucker et al., 1998). With this idea in mind, we estimate a series of gravity models to explain both mobility and collaboration phenomena, using a set of geographical, administrative and cognitive variables. In so doing, a thorough analysis to choose the adequate estimation method is performed. Thus, we estimate year by year cross-sectional gravity model which allows us assessing the changing role of selected bilateral variables in explaining both mentioned phenomena. Afterwards, the fitted values of these estimations are used to build our 
weights matrices to characterize cross-regional $R \& D$ diffusion patterns, which may explain a sizeable part of patent production heterogeneity across regions.

The 1990s and early 2000s witnessed an overwhelming emphasis given to knowledge spillovers to explain both increasing returns to scale, marked spatial disparities in regional economic growth and the agglomeration of technological activities in space (Audretsch and Feldman, 1996, 2004; Jaffe et al., 1993). This avenue of research underscored the critical role played by spatial proximity to access these technological and knowledge advantages (Capello and Lenzi, 2012). The advent of spatial econometric techniques (Anselin, 1988; Cliff and Ord, 1973) and the use of the regional KPF with spatial interactions between units (most notably, Acs et al., 1994; Anselin, 2000; Anselin et al., 1997; Bottazzi and Peri, 2003) featured a critical inflexion point among the related studies. Indeed, as stated by prominent scholars, there is no reason to assume that knowledge stops flowing because of regional borders (Audretsch and Feldman, 2004; Krugman, 1991). Therefore, spatial econometrics techniques and the spatial weight matrix notably improved the way in which such externalities were measured (Autant-Bernard and Massard, 2009).

Soon this oversimplified approach was overtaken and different concepts of proximity were also highlighted (Boschma, 2005; Capello, 2009; Capello and Lenzi, 2012; Rallet and Torre, 1995). Thus, an increasing number of scholars pointed out that, even at close spatial proximity, knowledge flows are not automatically received just by 'being there'. Rather, knowledge flows follow specific transmission channels, which are mainly based on market interactions and pecuniary externalities (Breschi and Lissoni, 2001a,b).

For instance, economists have long suspected that mobility of skilled employees transmits knowledge across organizations. This literature draws, among others, on earlier contributions such as Arrow (1962), Rosen (1972) or Stephan (1996), who pioneering stated that mobility of personnel between firms provides a principal way of spreading information. Indeed, mobility of skills across firms and institutions is likely to diffuse knowledge. When they move, skilled workers take their embodied knowledge with them. Hence, firms learn about other firms’ research after employing innovators who work or have worked in competing labs. In return, mobile employees acquire knowledge from their new colleagues and, in general, promote new combinations of 
knowledge (Laudel, 2003; Trippl and Maier 2010). ${ }^{1}$ Further, when skilled workers move from place to place, their knowledge and skills move as well (Breschi et al., 2010; Coe and Bunnell, 2003) and hence, may constitute a central way to establish crossregional linkages and spread knowledge and information across the space (in this later regard, see empirical applications by Boschma et al., 2009, and Simonen and McCann, 2008).

Besides, networks ${ }^{2}$ are critical for innovation. Cross-pollination of ideas, barters of tacit knowledge or the division of labour, have been regarded to be the underlying forces heading to network formation (Katz and Martin, 1997). In some instances, actors in regions build 'pipelines' in the form of alliances to benefit from knowledge hotspots around the world (Bathelt et al. 2004; Owen-Smith and Powell 2004). Although research collaboration can be considered as co-production of knowledge where inputs are transformed into outputs (Ponds et al, 2010), knowledge diffusion will occur as a by-product of such processes.

In light of these arguments and the abovementioned literature, as well as the weaknesses of the typical weights matrix formerly referenced, the main aim of the present inquiry is to model and estimate a regional KPF with 'neighbouring' effects built using meaningful data, such as, precisely, mobility and collaborations information, to construct such matrices. We acknowledge that this approach is, however, not new. Moreno et al. (2005a) and Parent and LeSage (2008), among others, have exploited the concept of technological proximity between regions vis-à-vis spatial proximity in estimates of cross-regional externalities. Their underlying logic lies on the idea that knowledge externalities flow easily among members of epistemic communities of scientists and technicians in highly specialized technological fields, irrespective of their geographical location, due to the fact that they share a specific knowledge background and common jargon and codes. Similarly, Kroll (2009) and Ponds et al. (2010) have built weight matrices that display the intensity of pair-wise relationships using

\footnotetext{
${ }^{1}$ Several empirical applications on the topic include, among others: Almeida and Kogut (1999), Corredoria and Rosenkopf (2010), Crespi et al. (2007), Fallick et al. (2006), Kim et al. (2006), Power and Lundmark (2004), Singh and Agrawal (2011) or Song et al. (2003).

${ }^{2}$ Note that the term 'network' used here is a simplification. As will be explained shortly, the bilateral structure of our co-patent data do not let us introducing the whole network structure in our estimations. Thus, we only consider direct networks - direct ties, and not the links that may happen between agents of two regions through, say, a third agent residing in a third region.
} 
collaborative research data across regions to proxy the social distance between them at the aggregate level. In this way, they show the importance of reflecting non-spatial, more meaningful measures of proximity across regions in estimating the effects of cross-regional knowledge flows on regional innovative performance. Maggioni et al. (2007) follows a similar approach, as spatial effects vis-à-vis network effects in the form of research collaborations are estimated in a spatial KPF framework. However, their approach reveals that when the spatial weight matrix is subtracted from the network matrix and a pure social matrix is considered on its own, important spatial effects remain unaccounted. Further examples include Morrocu et al. (2011a,b), who build a set of different weights matrices using various dimensions of proximity put to the forefront in the literature (see Boschma, 2005, as well as the French School of Proximity - Carrincazeaux et al., 2008). ${ }^{3}$

A main concern when using these meaningful matrices, however, is as follows: geography-based matrices are suitable to introduce exogenous variation into the models, allowing the identification of both endogenous and exogenous effects (Corrado and Figleton, 2012). Contrariwise, the necessary exogeneity of the r.h.s. variables might be compromised if weights matrices built with meaningful data are used (Harris et al., 2011). To the best of our knowledge, Peri (2005) is the most known work that, in a KPF framework, has tried to deal with this drawback. In his study, Peri (2005) utilizes gravitational models to estimate cross-regional citation flows and plug the estimated fitted values into a pseudo-weights matrix, which characterize knowledge flows across a set of European and North-American regions. Our own paper builds partially on Peri's contribution. Different from him, however, we rely on the weights matrix taken from the spatial econometrics toolkit to characterize pair-wise cross-regional interactions. In addition, our analysis relies on the actors more involved in innovation, namely, the inventors, and their mobility and networking practices. In sum, the principal novelty of our research with respect to the existing literature is the construction of cross-regional interaction matrices built using actual data. However, and contrary to usual approaches, we estimate spatial interaction models to get fitted values from actual data to plug them into our weights matrices. Again, this approach will also let us assessing the changing

\footnotetext{
${ }^{3}$ Other studies have estimated models with meaningful data to characterise the weights matrix, beyond the KPF framework. It is not our intention to review them all here, but a selection of the most outstanding ones can be found in Corrado and Fingleton (2012), Harris et al. (2011) or Pinske and Slade (2010).
} 
role of bilateral interaction variables over time in driving both spatial mobility and cross-regional co-patenting, for a large sample of European NUTS2 regions, which constitutes also a central aim of this research.

The outline of the paper is as follows. In section 2 we offer the theoretical framework for the analysis of regional patent intensity, as well as the determinants of mobility and collaborations across the space. Section 3 describes the data sources, variables construction and econometric issues, and section 4 provides the main results. Finally we conclude in section 5 .

\section{Framework of analysis}

\section{A model of regional innovation and external accessible knowledge}

This section sketches a formal model of knowledge production of firms in regions which benefit from accessing extra-regional pools of ideas by means of workers' mobility and bilateral technological ties. Our point of departure is the simplest specification of the knowledge production function of a representative firm ${ }^{4} k$ of region $i$ :

$$
Y_{k i t}=A_{i t} \cdot f\left(K_{k i t}, L_{k i t}\right)
$$

where $Y$ denotes innovation outputs, $K$ denotes R\&D inputs and $L$ the skilled labour force of a representative firm $k$ in region $i$ at time $t$.

Moreover, firms' innovation output is allowed to depend on an R\&D productivity index specific to each region, $A$. For simplicity, it is assumed that the KPF follows a CobbDouglas functional form:

$$
Y_{k i t}=A_{i t} \cdot K_{k i t}^{\beta} \cdot L_{k i t}^{\alpha}, \quad 0<\alpha<1, \quad 0<\beta<1, \quad \alpha+\beta=1
$$

\footnotetext{
${ }^{4}$ In our theoretical exposition, we mainly talk about firms, though research centres and universities could also be included as central innovative agents of regions.
} 
Aggregating all over firms in region $i$ yields to

$$
Y_{i t}=e^{C} \cdot A_{i t} \cdot K_{i t}^{\beta} \cdot L_{i t}^{\alpha},
$$

where $Y_{i t}$ denotes now the aggregated innovation output of region $i, K_{i t}$ the aggregated R\&D expenditures, $L_{i t}$ the sum of scientists and technologists across all the organizations, and $e^{C}$ denotes the constant term capturing the impact of all common factors affecting innovation across all the sample of regions. In order to guarantee reliable results in the estimations, the regional observations need to be comparable in size: equation (3) is pre-multiplied by a factor of $1 / N$, where $N$ is the total population of each region. That is,

$$
y_{i t}=e^{C} \cdot A_{i t} \cdot k_{i t}^{\beta} \cdot l_{i t}^{\alpha}
$$

where $y=Y / N, k=K / N$, and $l=L / N$. In this way, the innovative intensity of regions depends on R\&D expenditures per capita and the number of scientists and technologists as a proportion of the total population.

The R\&D productivity index, $A_{i t}$, is allowed to depend on local interactions giving firms access to knowledge from their immediate vicinity - networks, technological spillovers, local labour mobility - as well as from more distant pools of ideas. Our focus on cross-regional interactions as well as the macro data at hand precludes us to observe the effect of micro-interactions at the local level and their effect on firms' performance. In consequence, the R\&D productivity index is assumed to depend on the external-to-the-region stock of knowledge available for firm $k$ in region $i$ at time $t$, and some general locational advantages of region $i$, proxied by a regional fixed-effect, $e^{\delta_{i}}$.

Let us denote SK as the stock of knowledge accumulated in regions other than $i$ and accessible to all the firms in region $i$ at time $t$. If knowledge accessible in one region was perfectly and immediately diffusible to all other regions, we would consider the external stock of knowledge accessible to region $i$ simply as the sum of the knowledge stocks in all other regions. However, since diffusion is not perfect and, as we discussed, follow specific channels based on market mechanisms and embodied in individuals - 
such as labour mobility of skilled individuals and networks of research collaboration, we assume that there is only a part of the stock generated in region, say, $j$ that is accessible to region $i$, which will depend upon the strength of the $i j$-interactions in time $t$, that is

$$
S K_{i t}=\left(\prod_{\substack{j=1 \\ j \neq i}}^{I} S K_{j t}^{\rho^{m} \widetilde{\sigma}_{i j, t}^{m}}\right)\left(\prod_{\substack{j=1 \\ j \neq i}}^{I} S K_{j t}^{\rho^{n} \sigma_{i j, t}^{n}}\right)
$$

where $\omega_{i j, t}^{m}$ and $\omega_{i j, t}^{n}$ are bilateral weights that measure the strength of the interactions between region $i$ and region $j$ by means of, respectively, spatial mobility of the skilled labour force and geographical collaboration links. $\rho^{m}$ and $\rho^{n}$ are the output elasticities of the potential of, respectively, mobility and collaborations to spread R\&D stocks across European regions and therefore constitute the parameters of interest to be estimated in the present paper.

Next, expressing (5) in logs and substituting it into the log-transformation of (4), yields to

$$
\ln y_{i t}=c+\beta \ln k_{i t}+\alpha \ln l_{i t}+\rho^{m} \cdot \sum_{j \neq i} \omega_{i j, t}^{m} \ln S K_{j t}+\rho^{n} \cdot \sum_{j \neq i} \omega_{i j, t}^{n} \ln S K_{j t}+\delta_{i}+\varepsilon_{i t}
$$

where a well-behaved error term is now added, $\varepsilon_{i t}$.

As can be observed in (6), we need to measure the intensity of bilateral linkages in the form of bilateral mobility of skilled workers and technological collaborations, $\omega_{i j, t}^{m}$ and $\omega_{i j, t}^{n}$ respectively, for each regional pair, in order to calculate the stock of external accessible R\&D.

Hence, as we will show in the empirical section, our framework of analysis encompasses two stages: we first estimate the magnitude of the interactions for each pair of regions $\left(\omega_{i j, t}^{m}\right.$ and $\left.\omega_{i j, t}^{n}\right)$ using data both on mobility and co-patenting across 
regions as a function of a set of explanatory bilateral variables; and secondly we use the fitted values of these estimations to infer the impact of the external knowledge in equation (6) through the parameters $\rho^{m}$ and $\rho^{n}$. Thus, one main contribution of the present paper is to let the intensity of these linkages to be estimated by a number of bilateral characteristics of the regions affecting geographical mobility and collaboration patterns, to which we turn next.

\section{Knowledge interactions across-regions: a gravity approach}

\section{Knowledge interactions and mobility of inventors}

Our primary interest lies on a linear utility model where the inventor's utility of working and living in a location $i$ has a deterministic part common to all the inventors, $u$, and an individual-specific stochastic component, $\varepsilon_{i}^{k}$. Specifically, $k$ 's utility of working in location $i$ can be expressed as

$$
U_{i}^{k}=u\left(E_{i}\right)+\varepsilon_{i}^{k}
$$

Define the deterministic part $u$ as a function of a vector of amenities and economic variables $\left(E_{i}\right)$ of the $i$-th region affecting $k$-th utilities of that region. Individuals are rational, so their decision to move from one location to an alternative one will be based on a comparison between the expected utilities of the two locations. An individual will decide to migrate from location $i$ to location $j$ if the expected utility on the destination location is greater than the expected utility at the origin location minus the costs of relocating, which depend upon a set of geographical, administrative and cognitive distances, $D_{i j}$ :

$$
E\left(U_{j}^{k}\right)>E\left(U_{i}^{k}\right)+C\left(D_{i j}\right)
$$

When condition (8) holds, we define a variable $M_{i j}^{k}$ being equal to 1 , and 0 otherwise. Thus, for individual $k$ to migrate from location $i$ to location $j$ (and not to any other location $r$ ), the move must lead to higher expected utility and must mean that there 
were no alternative moves that would have provided a larger improvement. By aggregating individual movements by region and employing a very general gravity-type model specification, we can write:

$$
M_{i j}=f\left(E_{i}, E_{j}, D_{i j}\right)
$$

where $D_{i j}$ is a set of bilateral distance variables widely applied in gravity models of immigration. More specifically,

$$
D_{i j}=G_{i j}^{\varphi} \cdot e^{\psi_{i j}} \cdot T_{i j}^{\tau} \cdot e^{\gamma_{i j}}
$$

where $G_{i j}$ is the euclidean distance between the $i$-th and the $j$-th centroids, which is likely to negatively affect bilateral inventors' mobility because, among other reasons: (i) information on the destination location is more imperfect as the physical distance increases, (ii) transportation costs are likely to be larger, and (iii) regular encounters with family, friends and former colleagues will be more sparse in time at larger geographical distances. However, these effects are less likely to dominate in contiguous regions, and so, a dummy denoting the regions sharing a common border is also included, $e^{\psi_{i j}}$. On the other hand, technological proximity, $T_{i j}$, is included in order to proxy to what extent cognitive similarity (a shared, related, and complementary knowledge base) explains mobility across physically distant epistemic communities. Finally, a dummy variable indicating whether two regions belongs to the same country, $e^{\gamma_{i j}}$, is also introduced, in order to control for institutional, cultural or linguistic effects in the mobility decisions of inventors.

Next, since the set of push and pull region-specific variables possibly influencing crossregional mobility, $E_{i}$ and $E_{j}$, is likely to be large, we introduce origin and destination fixed-effects, $e^{\delta_{i}}$ and $e^{\lambda_{j}}$, and focus only on the abovementioned bilateral variables. As shown by Anderson and van Wincoop (2003), the inclusion of origin and destination fixed-effects in gravity models accords with theoretical concerns regarding the correct specification of these models, which translates into more consistent estimations. Thus, 
introducing origin and destination fixed effects in equation (10), we obtain our basic gravity model:

$$
M_{i j}=e^{\beta_{0}} \cdot G_{i j}^{\varphi} \cdot e^{\psi_{i j}} \cdot T_{i j}^{\tau} \cdot e^{\gamma_{i j}} \cdot \prod_{i=1}^{I} e^{\delta_{i}} \cdot \prod_{j=1}^{J} e^{\lambda_{j}} \cdot \varepsilon_{i j}
$$

where $e^{\beta_{0}}$ is a constant term capturing the impact of all common factors affecting mobility across all the sample of regions and $\varepsilon_{i j}$ a well-behaved error term.

Knowledge interactions and technological collaborations

As it is customary in the recent literature on network formation (Autant-Bernard et al., 2007; Cassi and Plunket, 2010; Mariani, 2004; Paier and Scherngell, 2011; Ter Waal, 2011), we describe the payoffs of collaborating - in our specific case, co-patenting - as:

$$
\pi^{k h}=f\left(X^{k}, X^{h}\right)+\varepsilon^{k h} .
$$

with $\varepsilon^{k h}$ being a pair-wise specific stochastic term. For each pair of inventors, $k$ and $h$, a link is formed if and only if the associated payoffs of collaborating are, at least, expected to be positive, $\pi^{k h}>0$. Hence, the payoffs of collaborating would depend upon $k$ 's and $h$ 's observable characteristics, $X^{k}$ and $X^{h}$. They may refer to $k$ 's and $h$ 's talent, productivity or willingness to collaborate, but they may also refer to the features of the institution, city or region where they work that may affect their common likelihood to collaborate with each other. More specifically, individuals $h$ and $k$ will decide to collaborate when the associated payoffs of collaborating are greater than the costs of doing so, $C\left(D^{k h}\right)$,

$$
\pi^{k h}>C\left(D^{h k}\right)
$$


When condition (13) holds, we define a variable $N_{i j}^{k h}$ being equal to 1 , and 0 otherwise. By aggregating all individual decisions by pairs of regions, we end up specifying a gravity model of regional collaboration in the form of

$$
N_{i j}=f\left(X_{i}, X_{j}, D_{i j}\right)
$$

where $N_{i j}$ is the sum of individual choices of inventors from region $i$ collaborating with someone from region $j$, which depends on the characteristics of a representative inventor of region $i\left(X_{i}\right)$ and the characteristics of a representative inventor of region $j$ $\left(X_{j}\right)$. For the same reasons abovementioned, the features of representative inventors in the $i$-th and the $j$-th regions are proxied by origin and destination fixed-effects, $e^{\delta_{i}}$ and $e^{\lambda_{j}}$, while focusing only on $D_{i j}$, which is again a set of bilateral distance variables widely applied in gravity models of spatial interactions. More specifically,

$$
D_{i j}=G_{i j}^{\varphi} \cdot e^{\psi_{i j}} \cdot T_{i j}^{\tau} \cdot e^{\gamma_{i j}}
$$

where $G_{i j}$ is the euclidean distance between the $i$-th and the $j$-th centroids, which is likely to negatively affect inventors' collaborations. Arguably, spatial proximity enables the formation of formal networks and collaborations: it facilitates the screening of potential partners (Storper and Venables, 2004), ease the managing and administration of the common project, and smoothes monitoring of partners' fulfillments. A dummy denoting the regions sharing a common border is also included, $e^{\psi_{i j}}$. Technological proximity, $T_{i j}$, is introduced in order to proxy to what extent cognitive similarity (a shared, related, and complementary knowledge base) explains co-patenting across physically distant epistemic communities. Finally, again, a dummy variable indicating whether two regions belongs to the same country or not, $e^{\gamma_{i j}}$, is also introduced. All in all, the following gravity-type model for the case of cross-regional collaborations is also going to be estimated:

$$
N_{i j}=e^{\beta_{0}} \cdot G_{i j}^{\varphi} \cdot e^{\psi_{i j}} \cdot T_{i j}^{\tau} \cdot e^{\gamma_{i j}} \cdot \prod_{i=1}^{I} e^{\delta_{i}} \cdot \prod_{j=1}^{J} e^{\lambda_{j}} \cdot \varepsilon_{i j}
$$


where $e^{\beta_{0}}$ is a constant term capturing the impact of all common factors affecting collaboration across all the sample of regions and $\varepsilon_{i j}$ a well-behaved error term.

\section{Empirical application}

\section{Data and variables construction}

Patent data per million population, from the REGPAT database (January 2010 edition), is used to proxy regional innovative intensity (in particular, $\mathrm{EPO}^{5}$ patents, fractional counting) - patent data correspond to the years 2000 to 2005. In spite of their shortcomings (Griliches, 1991; Verspagen and Schoenmakers, 2004), patent data have proved reasonably useful for proxying inventive activity. Since these data are prone to exhibit lumpiness from year to year, we have averaged out patent figures. Thus, a threeyear moving average is computed for every observation, thereby mitigating the effects of annual fluctuations in this variable, especially in those less populated areas. ${ }^{6}$

Proxies for the two main inputs of the regional KPF are also elaborated. R\&D expenditures per capita are computed by CRENoS. Specifically, data were collected from Eurostat and some National Statistical Offices, with some elaboration for regions in specific countries (Belgium, Greece, Netherlands, Switzerland). Human capital is measured as the population with tertiary education (population aged 15 and over by ISCED level of education attained) over overall regional population and is again elaborated by CRENoS, collected from Eurostat. The stock of R\&D of each region, which will be used to compute the available external stock of knowledge, is proxied using $\mathrm{R} \& \mathrm{D}$ data. The accumulation of $\mathrm{R} \& \mathrm{D}$ is described as $\triangle R \& D=R \& D_{t}-\delta R \& D_{t-1}-$ see Peri (2005) - where $\delta$ is an arbitrary depreciation rate set at 5\%. Other depreciation rates, however, do not alter the results. The initial stock of $\mathrm{R} \& \mathrm{D}$ has been calculated using the perpetual inventory method, $R \& D_{0}=R \& D_{t-n} /(g+\delta)$, where $R \& D_{t-n}$ is the first year for which the data were available, and $g$ is the geometric average annual growth rate of R\&D expenditure between 1996 and 1998. All the variables, as well as

\footnotetext{
${ }^{5}$ EPO stands for European Patent Office.

${ }^{6}$ Thus, the 2000 observations include averaged data from 2000 to 2002, whereas the 2005 observations include data from 2005 to 2007.
} 
the remaining controls, are lagged one period in order to lessen endogeneity problems due to system feedbacks. Other controls include population density and population density squared, and specialization and concentration indexes - computed using patent data broken down into technological sectors (Schmoch, 2008). More specifically the specialization and the concentration index of industries are constructed using patents from $30 \mathrm{IPC}^{7}$ technological sectors. To calculate the technological specialization index, we employ the following formula

$$
S p I n_{i t}=\frac{1}{2} \sum_{s}\left|\frac{P A T_{i S t}}{P A T_{i t}}-\frac{P A T_{I S t}}{P A T_{I t}}\right|,
$$

where PAT is the number of patents in each region i for each sector $S$, expressed as a difference for the whole sample of regions $(I)$. In a similar vein, the concentration index is built as follows:

$$
\operatorname{ConIn}_{i t}=\sum_{S t}\left(P A T_{i S t} / P A T_{S t}\right)^{2}
$$

In addition we also include regional fixed-effects, which allow us to control for important time-invariant confounders that might have biased previous estimates of the regional KPF.

Data to build our 'weights' matrices and the dependent variables of the gravity models come also from EPO patents retrieved from the REGPAT database (January 2010 edition). Three-year moving time-windows are computed, and are lagged one period with respect to the stock of regional $\mathrm{R} \& \mathrm{D}$. This way, if per capita patent data are computed gathering data from $\mathrm{t}$ to $\mathrm{t}+2$, the stock of $\mathrm{R} \& \mathrm{D}$ corresponds to the year $\mathrm{t}-1$, whereas the mobility and collaborations weights matrices are computed using threeyear time-windows from $\mathrm{t}-4$ to $\mathrm{t}-2 .^{8}$ These time lags are introduced again to minimize endogeneity and reverse causality problems. Whereas purely geographical weights

\footnotetext{
${ }^{7}$ International Patent Classification.

${ }^{8}$ As it will be explained later on, the technological distance used as one of the r.h.s. variables of the gravity models is computed using 3-year time windows as well. Again, the windows are time-lagged, and, continuing with our example, they correspond to the years t-7 to t-5. Note, therefore, that the sets of variables corresponding to each estimation step never overlap in time.
} 
matrices can be assumed to be clearly exogenous, our matrices are not, as the structure of collaborations and mobility is likely to be related to patterns of patenting. Clearly, however, our weights matrices have the advantage of bearing a direct relation with the theoretical conceptualization of the structure of spatial dependence, rather than an adhoc description of a spatial pattern based on geography. In addition, exogenous variables are used in our gravity-type estimations to capture, to some extent, the exogenous component of both mobility and networks and plug it into both weights matrices. We turn next to the description of the gravity variables.

Our model of geographical mobility of inventors is estimated year by year, from 1996 to 2001 (both inclusive). As already stated in the introductory section, this approach allows us assessing the changing role of spatial and cognitive bilateral variables, such as geography, in driving this phenomenon. The dependent variable is built by fullcounting the movements of inventors crossing regional borders, data computed within 3-year time-windows. ${ }^{9}$ We therefore construct mobility asymmetrical matrices of 269 rows and 269 columns for each time window, where each of the elements in the matrix is the number of inventors moving from region $j$ to region $i$. If an inventor moves more than once, or if she returns to her former region, we compute these movements as separate and independent. By definition movements from region $i$ to region $i$ do not exist and therefore the diagonal elements of the matrix are always zero. Mobility is computed through the changes observed in the region of residence reported by the inventor in patent documents from the EPO. Of course, in this way we only capture mobility if the inventor applies for a patent before and after the move, and so we probably underestimate real mobility. We compute each movement exactly in between the origin and the destination patents, but only if there is a maximum time lapse of five years between the two patents - otherwise, the time elapsed would be too large and the exact time of the move would be too uncertain.

A thorough disambiguation process of the names of the inventors in patents was carried out in order to track their mobility patterns, as it is done in Miguélez and GómezMiguélez (2011), among others. In brief, we first clean, harmonize and code all the

\footnotetext{
${ }^{9}$ Note, therefore, that the 1996-window corresponds to data from 1996 to 1998, whilst the 2001-window corresponds to data from 2001 to 2003.
} 
inventors' names and surnames. Afterwards, we test whether each pair of names belong to the same individual, using a wide range of characteristics, such as their address, the applicants and groups of applicants of their patents, their self-citations, or the technological classes to which their patents belong - up to 15 different tests were run.

The co-patenting gravity model is also estimated year by year, and cross-regional collaborations are computed within 3-year time-windows as well. EPO co-patents between inventors residing, at the time of the patent application, in different NUTS2 region, are used as a proxy for regional bilateral collaboration. Obviously, the underlying assumption is that co-patents reflect inventors' collaborative practices between non-co-located peers. Based on the addresses of the inventors appearing in the patent document, we compute the pair-wise number of collaborations between each pair of regions, and a matrix of 269 rows and 269 columns for each time window was also constructed. The elements of these matrices, and therefore the dependent variable of our gravity models, is simply the number of all technological collaborations within a given time window between two regions $i$ and $j$, irrespective of the number of inventors listed in each patent, being the diagonal elements of the matrix, again, always zeros. Because of the nature of a collaboration, the matrices are symmetrical by definition, meaning that the final number of observations reduces to $\left(\mathrm{N}^{*} \mathrm{~N}-1\right) / 2 .^{10}$

The explanatory variables of the gravity models coincide in both cases. These include: (i) the Euclidean distance between the regions' centroids, (ii) a dummy variable indicating whether the two region share a common border, and (iii) a dummy variable indicating whether the two regions belong to the same country or not. In addition, cognitive proximity is proxied by an index of technological dissimilarity (in our case, 1 minus technological similarity), being similarity measured as the uncentred correlation between regional vectors of technological classes of patents (Jaffe 1986).

Note, importantly, that our sample of 269 European NUTS2 regions is relatively large compared to previous studies and covers a high number of countries (EU-27 plus

\footnotetext{
${ }^{10}$ Note that, because of the use of co-patent data in this study, it is impossible to know whether crossregional collaborations occur between or within firms' boundaries. Studying the different role of these different types of cross-regional linkages would be an interesting issue that, unfortunately, we cannot approach using our current dataset. We thank one of the referees for rising this point.
} 
Norway and Switzerland). ${ }^{11}$ Table 1 provides summary statistics of the variables used for the KPF estimation, whereas tables 2 and 3 provide yearly figures for the mobility and collaborations dependent variables.

[Insert Tables 1, 2 and 3 about here]

Table 4 provides the correlation matrix corresponding to the KPF variables. Arguably, some pairs of variables show relatively large correlation coefficients (though "only" around 0.7). Introducing alternatively in the KPF estimations one or the other variable of each pair does not change to a large extent the quantitative results, though - results provided upon request. The correlation among the remaining independent variables is, in general, sufficiently small and collinearity does not pose a significant problem in our estimations. Note, importantly, that the correlation between the R\&D stocks weighted either by mobility or by networks is not particularly large, which was a potential concern when introducing both variables at the same time in the estimations.

[Insert Table 4 about here]

\section{Econometric issues}

A natural way to estimate the gravity models, equations (11) and (16), would be to apply a logarithmic transformation and OLS techniques. Santos Silva and Tenreyro (2006, 2010) show, however, that this standard procedure in a gravity model may induce a form of heteroskedasticity of the error term because of the log transformation of the data, and OLS would be inconsistent. In addition to this, the number of zeros in the dependent variables is relatively large, making a logarithmic transformation of these variables impossible. To address these issues, Santos Silva and Tenreyro (2006, 2010) suggest estimating the multiplicative form of the model by Poisson pseudo-maximum likelihood.

\footnotetext{
11 We have omitted the regions of Las Canarias, Ceuta, Melilla, Madeira, Açores, Guadeloupe, Martinique, Guyane and Reunion, as well as Malta and Cyprus, due to their distance from continental Europe. In addition, four Greek regions filed no patent applications in our period of analysis and so were removed from the study. We do not expect this omission to alter our results significantly.
} 
Further, their suggested estimators are particularly suitable in our case because our response variables are discrete, with a distribution that places the probability mass at non-negative integer values only, with data concentrated in a few small discrete values, right-tailed and intrinsically heteroskedastic, with variance increasing with the mean (Cameron and Trivedi, 1998). Again, count data models are more suitable in this framework.

The most basic type of count data model is derived from the Poisson distribution. However, the Poisson distribution assumes equidispersion - that is, the conditional variance equals the conditional mean. But the conditional variance often exceeds the conditional mean (Burger et al., 2009; Long, 1997), which is a clear symptom of overdispersion. As a result, the Poisson regression may lead to consistent but inefficient estimates (Burger et al., 2009), with standard errors biased downward (Cameron and Trivedi, 1998; Long, 1997). Over-dispersion tests, based on the significance of $\alpha$, the dispersion parameter, can be performed to guide our model choice.

An important issue is related to the disproportionate number of zero that our dependent variables contain. Although count data models are explicitly designed to deal with the presence of zeros, these zeros may come from different data generating processes. Specific estimation techniques might be therefore required, such as the use of zeroinflated models. In these models, the estimation process includes two parts: first the probability of observing mobility from $j$ to $i, \varphi$, is estimated by means of a probit or logit model, which is a function of certain characteristics - a set of covariates that predict the probability of belonging to the strictly-zero group; and second, the count data model is estimated for the probability of each count for the group that has non-zero probability.

In the following section, we thoroughly compare the performance of various types of count data models in order to choose the most appropriate estimation technique. 


\section{Results}

Our empirical analysis consists of two differentiated parts. First, in the following subsection we present the results of estimating the weights matrices $\omega_{i j}^{m}$ and $\omega_{i j}^{n}$ using data on mobility of skilled workers and technological collaborations between regions, and the selection criteria used among different count data models. Afterwards, we use these estimated values along with data on regional R\&D to estimate the elasticities $\rho_{m}$ and $\rho_{n}$ in equation (6).

\section{Estimation of knowledge interactions}

Model (i) in table 5 shows the OLS estimations of the gravity model of cross-regional mobility, included for comparison purposes, for the case of the time window 20012003. Besides, columns (ii) to (v) show, respectively, the Poisson Pseudo-Maximum Likelihood estimation (PPML), the Negative Binomial Pseudo-Maximum Likelihood (NBPML), the Zero Inflated Poisson Pseudo-Maximum Likelihood (ZIPPML) and the Zero-Inflated Negative Binomial Pseudo-Maximum Likelihood (ZINBPML), thereby accounting for the discrete nature of the dependent variable, the presence (or excess) of zeros, and over-dispersion. In particular, column (ii) takes into account the count data nature of dependent variable, whilst column (iii) also controls for over-dispersion. Finally, columns (iv) and (v) take also on board the disproportionate presence of zeros in the dependent variable for, respectively, the Poisson and negative binomial estimations. As a general conclusion, we observe that apart from the OLS estimation, the coefficient estimates are very similar for the rest of the cases in terms of significance and sign. The geographical distance and the technological/cognitive distance are negative, as expected, and strongly significant. We find that both greater geographical as well as cognitive distances between two regions tend to hamper knowledge workers' mobility. The results are in line to what is found in the regional migration literature at the European level (Crozet, 2004) as well as the results for the specific case of inventors (Miguelez and Moreno, 2012). In general, since the covariates are expressed in logarithmic form, the estimated coefficients can be interpreted as elasticities (Cameron and Trivedi, 1998). Meanwhile, sharing a common border and belonging to the same country foster the inter-exchange of inventors, as 
expected. Note, importantly, that geographical and cognitive distance tend to show smaller coefficient estimates in zero-inflated models, which might be a symptom of the upward bias introduced in their non-zero-inflated counterparts. We discuss this issue shortly.

\section{[Insert Table 5 about here]}

Being the OLS estimation disregarded in theoretical grounds, a first graphical way to assess the different performance of count data models and to help choosing the most suitable one is to look at the probability distribution and compare the expected probabilities to the observed probabilities. Figure 1 shows this. The points above the horizontal axis indicate an over-prediction of the probability of observing mobility, whilst points below the axis indicate under-prediction. Clearly, ZIPPML (labelled 'zip' in the graph) and ZINBPML ('zinb') seem to perform the best, as the difference between expected and observed probabilities tends to be lower for all the cases. Note, however, that the ZINBPML ('zinb') seems to slightly under-predict the zeros whilst the ZIPPML ('zip') seems to slightly over-predict the ones. In order to choose between these two estimation methods, more formal statistical tests can also be used, to which we turn next.

[Insert Figure 1 about here]

Broadly speaking, the ZIPNBML presents a lower AIC and a higher log-likelihood value (OLS set aside), which seems to indicate its superiority over the other methods in terms of fit. In addition to this, both over-dispersion tests and Vuong statistics (bottom of table 5) seem to clearly point to the use of ZINBPML to the detriment of the other estimation methods.

Table 6 presents the gravity estimations of co-patenting across regions in Europe, same period as before, same estimation techniques. Again, aside from the case of the OLS estimations, included for comparison purposes but disregarded on theoretical grounds, the coefficient estimates are comparable among estimation methods - it is worth noting, however, important differences in their magnitudes. In general, the results found accord 
with previous empirical findings in similar contexts (Hoekman et al, 2009; Maggioni et al., 2007).

[Insert Table 6 about here]

As before, the difference between the expected probabilities to the observed probabilities is plotted in figure 2. As can be seen, the conclusions for the case of crossregional cooperation slightly differ from before. All the models seem to over-predict the number of zeros, though ZIPPML (labelled 'zip') and ZINBPML ('zinb') largely outperforms PPML ('poisson') and NBPML ('nbreg'). Meanwhile, all the models seem to under-predict ones, being, in this order, ZIPPML ('zip') and ZINBPML ('zinb') outperforming the other methods. It seems, therefore, that ZIPPML ('zip') would be the chosen model based on the graphical representation of expected probabilities. We next turn to examining additional statistical tests in order to clarify this extreme and take a final decision.

[Insert Figure 2 about here]

Despite the former graphical results, statistical tests seem to point to the use of the ZINBPML again - see bootom of table 6, according to the AIC criteria, the value of the log-likelihood and the over-dispersion and Vuong statistics. In order to be as consistent as possible with the mobility case, we chose to estimate the gravity models of collaboration by means of ZINBPML, but we present robustness checks of the KPF estimation with ZIPPML estimations of both gravitational models, in order to study the stability and significance of the estimated parameters.

Finally, tables 7 and 8 show the ZINBPML estimations, respectively, for the case of mobility and networks, and from 1996 to 2001 (from the time window 1996-1998 to the time window 2001-2003). Interestingly enough, the coefficients barely change over time, which is, admittedly, an unexpected result. Note, however, that somehow the different estimations partially overlap so as to observe big differences between them. ${ }^{12}$

\footnotetext{
${ }^{12}$ Although origin and destination fixed effects fairly control for origin and destination important features in a cross-sectional setting, they do not so in a longitudinal framework. Thus, when a panel gravity model
} 
[Insert Table 7 and 8 about here]

\section{The impact of external accessible knowledge on innovation production}

Table 9 presents the results of the pooled OLS as well as the random and fixed effects estimation of the regional KPF, including the stock of knowledge in the external regions, weighted both by fitted mobility values and fitted networking values. ${ }^{13}$ At first sight results are consistent across methods of estimation in relation to the significance and sign of the core variables, namely $R \& D$ and human capital, as well as our focus variables. This is so irrespective of the consideration of control variables (columns (iv) to (vi)). However, the magnitude of their impact differs substantially from one method to another. ${ }^{14}$ Clearly, the point estimates of most of the variables are dramatically changed when regional fixed-effects are included, signalling the importance of timeinvariant unobserved heterogeneity. With the aim of using the most adequate model for the interpretation of our results, we use the Hausman test, which rejects the null hypothesis that individual effects are uncorrelated with the independent variables. This points to the preference of the fixed effect model - columns (iii) and (vi) - to the expense of the random-effects.

The elasticity of patents with respect to $R \& D$ expenditures when the fixed-effects estimations are carried out presents significant values (around 0.21), which is in line with the value obtained in the literature (Acs et al., 1994; Bottazzi and Peri, 2003; Jaffe, 1989). Additionally, the human capital parameter is significant and with the expected positive sign, with similar values to those reported elsewhere (around 0.19 as in Bottazi and Peri, 2003).

is estimated, and origin and destination are included, important time-variant origin and destination variables would also need to be included. This would imply including variables such as GDP per capita and other economic variables, amenities, and the like. Unfortunately, this kind of variables covering the whole sample of regions is not readily available. In addition to this, and more important, introducing variables such as the GDP will probably plague our first stage of endogeneity problems, which is precisely what we want to avoid. For these reasons, we prefer to estimate separate cross-sections and get the fitted values separately to plug them into our knowledge interaction matrices.

${ }^{13} \omega_{i j}^{m}$ and $\omega_{i j}^{n}$ have been row-standardized, as it is usually done in the spatial econometrics literature.

14 In principle, again, the coefficients can be interpreted as elasticities, since the variables in the regression are expressed in natural logarithmic form: the proportional increase in patenting activity in response to a $1 \%$ increase in a given explanatory variable. 
Column (vi) further includes additional control variables: population density, population density squared, and specialization and concentration indices. Population density is significantly positive, pointing to the presence of agglomeration and urbanization economies, and its quadratic form is also included, being negative. These results would indicate evidence that overly dense areas suffer several costs related to congestion effects of agglomeration (negative externalities). On the other hand, the specialization index is positive whereas concentration seems to affect negatively the innovative activity.

More important for our purposes are the significant and positive parameters obtained for the two variables proxying the available stock of knowledge from other regions. The elasticity of patenting activity with respect to $R \& D$ stocks in the rest of the European regions, weighted by the mobility of researchers between each pair of regions, presents a significant value of 0.012. Also positive, although of a greater magnitude, is the elasticity of patenting with respect to $R \& D$ stocks in the rest of European regions weighted by the intensity of collaborative networks across regions, with a value of 0.037 . Despite the difficulty of interpreting the magnitude of these elasticities, the results seem to confirm that the production of knowledge in regions depends not only on its own research efforts and internal factors, but also on the knowledge available in other regions, accessible through mobile inventors and bilateral collaborations. In addition, it seems that among the two mechanisms through which knowledge diffuses and which we have explicitly considered in this paper, regions benefit more from external knowledge stocks when the transmission is through networks of collaboration than through the movement of highly skilled workers. The impact of the later is one third of the former.

Already in the design of the Innovation policy in a knowledge-based economy (European Commission, 2000, p. 5), the European Commission made emphasis on knowledge mobility, since "the importance of tacit and specialised knowledge calls for greater mobility of knowledge workers". Equally, it was highlighted that "European heterogeneity or variety can be exploited through networking of firms and scientists, to create a vibrant learning culture in which many different ideas and approaches are available as inputs to firms' innovation and learning” (p. 6). In our paper we have 
empirically confirmed that policies fostering mobility and collaborations across inventors allow higher innovation outputs. Thus, policies that facilitate the mobility of knowledge among firms, stimulate collaborations among firms in their knowledge activities and foster senior knowledge workers visiting other institutions, even when crossing the borders of a region, has a benefit for the whole EU.

According to Licht (2009), the importance of R\&D policies has already been underlined by the 3\% target of the Lisbon strategy, whereas for diffusion policies remain a further need for action for policy makers. This paper gives empirical confirmation that knowledge externalities flow easily among regions whose individuals are in contact thanks to the mobility of skilled workers or thanks to technological collaborations, irrespective of their geographical proximity, and so, policies with this target seems to be well founded.

In short, the empirical analysis undertaken here support the hypothesis concerning the importance of collaborations and, to a lesser extent, of labour mobility as the means fostering the geographical diffusion of knowledge. However, several extensions to this initial approach can next be made.

\section{Robustness checks}

In this section we summarize several robustness checks performed to study the stability and significance of the estimated parameters, and the results encountered so far. The initial checks refer to the way of constructing the two variables proxying the stock of $R \& D$ in external regions. Column (i) estimates our main equation with fitted values from previous gravity models for mobility and collaborations that have been estimated using the ZIPPML method. The coefficients and resulting conclusions are virtually unchanged. The same occurs when the actual values of collaborations and mobility, instead of the fitted ones, are used for the weights of the stock of $R \& D$ in external regions (column (ii)).

The remaining robustness checks are related to the role of physical proximity per se in the transmission of knowledge. In column (iii) we allow the production of knowledge in a region to depend not only on its own research efforts and internal factors, but also 
on the knowledge available in the physically close neighbouring regions. The latter is proxied by the sum of the R\&D stocks in the regions sharing a border, where each stock is divided by the number of contiguous regions (row-standardized weight matrix), as it is customary done in the related literature. As it is shown, the impact exerted by the knowledge available in the physically neighbouring regions is significantly positive and clearly of a much higher magnitude than that exerted thanks to the knowledge transmitted through networks of collaboration or mobility of inventors. Even though the related studies tend to interpret the estimates of cross-regional spatial effects as evidence of geographical knowledge spillovers (among many others, see: Bottazi and Peri, 2003; Moreno et al., 2005a, 2005b), we are reluctant to this interpretation because of the criticisms these matrices have received due to the lack of theoretical foundations behind their specification. Contrarily, a reasonable interpretation we can actually make is in terms of the role of physical distance in explaining both mobility and co-patents. Most probably, inventors place a high value on locating close to their former colleagues, workmates, friends and acquaintances when they decide to move, from whom they can get constant inflows of information about job and business opportunities, as well as technical solutions. Equally, and despite of the increasing use of ICT technologies which allow communications across distances, still the costs of searching potential partners, and those derived from negotiation between the partners, formation of contracts, agreement on the amount of knowledge and information that have to be exchanged, managing and administration of the common project, as well as monitoring of partners' fulfilments, are likely to be less significant if agents have the chances to interact and meet frequently because of physical co-location. In sum, the different effects at work are likely to occur at short spatial distances and almost impossible to disentangle from one another. We acknowledge that further research to ascertain what drives these large coefficients is definitely needed. Thus, we claim that an important part of knowledge diffusion across regions in the knowledge production process are driven by ties of research collaborations and labour mobility. Column (iv) includes the three variables at a time, that is, the stock of knowledge in the remaining regions weighted by mobility, collaborations and spatial contiguity. In principle, one would expect the values of the parameter of the stock of $R \& D$ in the contiguous neighbouring regions to fall significantly when the other two variables are included in the regressions. This appears not to be true, since the parameter decreases but only slightly (from 0.52 to 0.47 ). It is worth mentioning though that our focal variables 
remain strongly significant even when purely spatial effects are introduced - though with slightly smaller coefficient estimates, as it is the case of the spatial $R \& D$ variable. It seems, therefore, that the three variables partially overlap. This points to the need to undertake further research to investigate the additional actual channels by which knowledge diffuses over the space, beyond contiguity and physical proximity per se. Finally, column (v) repeats our main estimation but including the regional stock of $R \& D$ per capita instead of the $R \& D$ expenditures per capita. In this case, the own $R \& D$ parameter is considerably larger, though the conclusions and main results regarding the remaining parameters are maintained.

\section{Concluding remarks}

Although knowledge and innovation are well recognized as critical pillars of 'smart growth' in Europe, the right strategies that can help the continent to move in this direction are not so evident. Arguably, a pivotal element to ensure regional economic growth lies in accessing external sources of knowledge and facilitating interactive learning and interaction in innovation. This knowledge diffusion can take place through diffusive patterns based on knowledge externalities, that rely on informal transmission channels, relatively bounded in space, but also through intentional relations such as spatial mobility of skilled employees and geographical networks of research collaboration (Moreno and Miguelez, 2012; ESPON, 2012)

The present inquiry is a first step in this direction and estimates a KPF where geographical interactions occurring across regions in the production of knowledge are introduced. Specifically, a more meaningful modelling of these interactions through inventors' mobility and co-patenting data has been considered when building weights matrices to describe the strength of bilateral knowledge relations across European regions. We acknowledge that a thorough spatial econometric analysis could be performed estimating our production function by means of SAR and SEM models. Indeed, inventors' mobility and collaboration data, and the approach we have suggested here - the gravity estimations, could be used to build weights matrices to estimate these spatial lag models and spatial error models (Anselin, 1988). Our own future research will definitely go in this direction. 
We also acknowledge that geographical mobility and collaborations are intrinsically interrelated and these interrelations could affect our results. Further research should contemplate how to incorporate them in our empirical model through, for instance, Structural Equation Models, where mobility and collaborations influences each other and the geographical diffusion of knowledge at the same time.

We find that both collaborations and, to a lesser extent, mobility, foster knowledge diffusion across European regions. Hence, from a policy perspective, these results illustrate that, not only $R \& D$ and human capital efforts are important to generate innovations at the regional level, but also the degree of connectivity of agents with the outside world, which give them access to global knowledge hotspots is useful for innovation. Such idea of connectivity, among others, is precisely in the core of the 'smart specialisation' strategy recently launched by the European Commission (McCann and Ortega-Argilés, 2011).

\section{References}

Acs, Z.J., Audretsch, D.B. and Feldman, M.P. (1994) R\&D spillovers and recipient firm size, Review of Economics and Statistics 76(2): 363-367.

Aghion, P. and Howitt, P. (1998) Endogenous Growth Theory, MIT Press.

Almeida, P. and Kogut, B. (1999) Localisation of knowledge and the mobility of engineers in regional networks, Management Science 45(7), pp. 905-917.

Anderson, J. E. and van Wincoop, E., (2003) Gravity with gravitas: a solution to the border puzzle, American Economic Review, 93, 170-192.

Anselin, L. (1988) Spatial Econometrics: Methods and Models. Kluwer Academic Publishers, The Netherlands;

Anselin L., Varga A. and Acs Z. (1997) Local Geographic Spillovers between University Research and High Technology Innovations, Journal of Urban Economics 42, 422-48;

Anselin, L. (2000) Geographical Spillovers and University Research: A Spatial Econometric Perspective, Growth and Change, 31(4), pp. 501-515.

Arrow, K.J. (1962) The Economic Implications of Learning by Doing. Review of Economic Studies 29(3): 155-173.

Audretsch, D.B. and Feldman, M.P. (1996) R\&D Spillovers and the geography of innovation and production, American Economic Review 86(3): 630-640.

Audretsch, D.B. and Feldman, M.P. (2004) Knowledge Spillovers and the Geography of Innovation, in V. Henderson and J. Thisse (Eds) Handbook of Urban and regional Economics, Volume 4.

Autant-Bernard, C.; Billand, P.; Frachisse, D. and Massard, N. (2007) Social distance versus spatial distance in $R \& D$ cooperation: Empirical evidence from European 
collaboration choices in micro and nanotechnologies, Papers in Regional Science 86(3): 495-519.

Autant-Bernard, C. and Massard, N. (2009) Underlying mechanisms of knowledge diffusion. IAREG Working Paper 4.7

Bathelt, H., Malberg, A. and Maskell, P. (2004) Clusters and knowledge: local buzz, global pipelines and the process of knowledge creation, Progress in Human Geography 28(1): 31-56.

Boschma, R. (2005) Proximity and Innovation: A Critical Assessment, Regional Studies 39(1): 61-74.

Boschma, R., Eriksson, R. and Lindgren, U. (2009) How does labour mobility affect the performance of plants? The importance of relatedness and geographical proximity, Journal of Economic Geography 9(2), pp. 169-190.

Bottazzi, L. and Peri, G. (2003) Innovation and spillovers in regions: Evidence from European patent data. European Economic Review 47(4): 687-710.

Breschi S, Lenzi C, Lissoni F, Vezzulli A (2010) The geography of knowledge spillovers: the role of inventors' mobility across firms and in space. In: Boschma R, Martin R (eds) The Handbook of Evolutionary Economic Geography, Cheltenham: Edward Elgar, pp. 353- 369

Breschi, S. and Lissoni, F. (2001a) Localised knowledge spillovers vs. innovative millieux: Knowledge “tacitness” reconsidered. Papers in Regional Science 80(3): 255-273.

Breschi, S. and Lissoni, F. (2001b) Knowledge spillovers and local innovation systems: A critical survey, Industrial and Corporate Change 10(4): 975-1005.

Breschi S. and Lissoni F. (2004) Knowledge networks from patent data: methodological issues and research targets, in Moed H., Glänzel W. and Schmoch U. (Eds) Handbook of Quantitative Science and Technology Research: The Use of Publication and Patent Statistics in Studies of S\&T Systems, pp. 613-643. Springer Verlag, Berlin;

Breschi S. and Lissoni F. (2006) Cross-firm inventors and social networks: localised knowledge spillovers revisited, Annales d'Economie et de Statistique, 79-80;

Breschi S. and Lissoni F. (2009) Mobility of skilled workers and co-invention networks: an anatomy of localized knowledge flows, Journal of Economic Geography 9, 43968 ;

Burger M., van Oort F. and Linders G. (2009) "On the Specification of the Gravity Model of Trade: Zeros, Excess Zeros and Zero-inflated Estimation”, Spatial Economic Analysis 4(2), pp. 167-190;

Cameron A.C., Trivedi P.K., 1998. Regression Analysis of Count Data. Econometric Society Monograph No.30, Cambridge University Press.

Capello, R. (2009) Spatial spillovers and Regional Growth: A cognitive approach, European Planning Studies, 17, 5, pp. 639-658.

Capello, R. and Lenzi, C. (2012) Knowledge, Innovation and Economic Growth: Spatial Heterogeneity in Europe, unpublished manuscript.

Carrincazeaux C., Lung Y. and Vicente J. (2008) The Scientific Trajectory of the French School of Proximity:bInteraction- and Institution-based Approaches to Regional Innovation Systems, European Planning Studies 16, 617-628.

Cassi, L. and Plunket, A. (2010) The determinants of co-inventor tie formation: proximity and network dynamics, Papers in Evolutionary Economic Geography (PEEG) 1015, Utrecht University, Section of Economic Geography.

Cliff, A.D. and Ord, J.K. (1973) Spatial autocorrelation. London: Pion 
Coe, N.M. and Bunnell, T. (2003) 'Spatializing' knowledge communities: towards a conceptualisation of transnational innovation networks'. Global Networks 3(4): 437456.

Corrado, L. and Fingleton, B. (2012) Where Is The Economics In Spatial Econometrics?, Journal of Regional Science, 52(2), 210-239.

Corredoira R. A. and Rosenkopf L. (2010) Should Auld Acquaintance Be Forgot? The Reverse Transfer of Knowledge through Mobility Ties, Strategic Management Journal 31(2), pp. 159-181.

Crespi G., Geuna A. and Nesta L. (2007) The mobility of university inventors in Europe, Journal of Technology Transfer 32, pp. 195-215.

Crozet M., 2004. Do migrants follow market potentials? An estimation of a new economic geography model. Journal of Economic Geography 4, 439-458.

ESPON (2012) Knowledge, Innovation, Territory, Final Report, KIT/ESPON

European Commission (2000) Innovation policy in a knowledge-based economy, Publication no. EUR 17023 of the Commission of the European Communities, Luxembourg.

Fallick, B., Fleischman, C.A. and Rebitzer, J.B. (2006) Job-Hopping in Silicon Valley: Some Evidence Concerning the Microfoundations of a High-Technology Cluster, The Review of Economics and Statistics, 88(3), pp. 472-481.

Griliches Z (1991) Patent Statistics as Economic Indicators: A Survey. NBER Working Papers No. 3301. National Bureau of Economic Research

Harris, R., Moffat, J., Kravtsova V. (2011) In Search of 'W', Spatial Economic Analysis 6(3), pp. 249-270.

Hoekman, J.; Frenken, K. and van Oort, F. (2009) "The geography of collaborative knowledge production in Europe” The Annals of Regional Science, 43(3): 721-738.

Jaffe A. B. (1986) Technological opportunity and spillovers of R\&D: evidence from firms patents, profits and market value, American Economic Review 76, 984-1001;

Jaffe, A.B. (1989) Real effects of academic research, American Economic Review 79, pp. 957-970.

Jaffe AB, Trajtenberg M, Henderson R (1993) Geographic localisation of knowledge spillovers as evidenced by patent citations. Quarterly Journal of Economics 108: 577-598

Jones, C. (1995) “R\&D-Based Models of Economic Growth”, Journal of Political Economy 103: 759-784.

Katz, J.S. and Martin B.R. (1997) What is research collaboration?, Research Policy 26, pp. 1-18.

Kim, J., Lee, S.J. and Marschke, G. (2006) International Knowledge Flows: Evidence from an Inventor-Firm Matched Data Set, NBER Working Paper No. 12692.

Kroll, H. (2009) Spillovers and proximity in perspective: A network approach to improving the operationalisation of proximity. Working Papers Firms and Regions No. R2/2009, Fraunhofer ISI.

Krugman, P. (1991): Geography and Trade. Cambridge, Massachusetts: MIT Press.

Laudel G. (2003) Studying the brain drain. Can bibliometric methods help?, Scientometrics 57, 215-37;

Licht, G. (2009) How to better diffuse technologies in Europe, Knowledge Economists Policy Brief, 7.

Long J. S. (1997) Regression Models for Categorial and Limited Dependent Variables. Thousand Oaks, CA, Sage. 
Maggioni, M.A., Nosvelli, M. and Uberti, T.E. (2007) Space versus networks in the geography of innovation: A European analysis. Papers in Regional Science 86(3): 471-493.

Mariani, M. (2004) Location of research and collaboration among inventors in the chemical industry, in: F Cesaroni, A Gambardella \& W Garcia-Fontes (Eds.), R\&D, Innovation and Competitiveness in the European Chemical Industry, Kluwer Academic publishers, Dordrecht.

Marrocu, E, R. Paci, S. Usai (2011a) Proximity, Networks and Knowledge Production in Europe. WP CRENoS WP11-09.

Marrocu, E., R. Paci, S. Usai (2011b) The complementary effects of proximity dimensions on knowledge spillovers. WP CRENoS WP11-21.

McCann P, Ortega-Argilés R (2011) Smart specialisation, regional growth and applications to EU cohesion policy. Document de treball de l'IEB 2011/14, Institut d'Economia de Barcelona

Miguélez, E. and Gómez-Miguélez, I. (2011) Singling out individual inventors from patent data, IREA Working Paper 2011/05.

Miguelez, E. and Moreno, R. (2012) What Attracts Knowledge Workers? The Role of Space, Social Connections, Institutions, Jobs and Amenities, IREA Working Paper 2012/04.

Moreno, M. and Miguelez, E. (2012) A relational approach to the Geography of Innovation: A typology of regions, Journal of Economic Surveys, Vol. 26, pp.492-516.

Moreno R., Paci R. and Usai S. (2005a) Spatial spillovers and innovation activity in European regions, Environment and Planning A 37, 1793-812;

Moreno R., Paci R. and Usai S. (2005b) Geographical and sectoral clusters of innovation Europe, Annals of Regional Science 39, 715-39;

Owen-Smith J, Powell WW (2004) Knowledge networks as channels and conduits: the effects of spillovers in the Boston biotechnology community. Organization Science 15(1): 5- 21

Paci, R. and Usai, S. (2000) Technological Enclaves and Industrial Districts: An Analysis of the Regional Distribution of Innovative Activity in Europe, Regional Studies, 34(2), pp. 97-114.

Paier, M. and Scherngell, T. (2011) "Determinants of Collaboration in European R\&D Networks: Empirical Evidence from a Discrete Choice Model” Industry \& Innovation 18(1): 89-104.

Parent, O. and LeSage, J.P. (2008) Using the variance structure of the conditional autoregressive spatial specification to model knowledge spillovers. Journal of Applied Econometrics 23(2): 235-256.

Peri, G. (2005) Determinants of Knowledge Flows and Their Effect on Innovation. The Review of Economics and Statistics 87(2): 308-322.

Pinske, J., and Slade, M. (2010): «The future of spatial econometrics», Journal of Regional Science, 50:103-117.

Ponds R., van Oort F. and Frenken K. (2010) Innovation, spillovers and universityindustry collaboration: an extended knowledge production function approach, Journal of Economic Geography 10, 231-55;

Power, D. and Lundmark, M. (2004) Working through knowledge pools: labour market dynamics, the tranference of knowledge and ideas, and industrial clusters, Urban studies 41, pp. 1025-1044.

Rallet, A., Torre, A. (1995) Économie Industrielle er Économie Spatiale, Economia, Paris, pp. 273-293. 
Rincke, J. (2010) A commuting-based refinement of the contiguity matrix for spatial models, and an application to local police expenditures, Regional Science and Urban Economics, 40, pp. 324-330.

Romer P.M. (1986) Increasing Returns and Long-run Growth. Journal of Political Economy 94(5): 1002-1037.

Romer P.M. (1990) Endogenous Technological Change. Journal of Political Economy 98(5): 71-102.

Rosen, S. (1972) Learning and expertise in the labor market, The Journal of Human Resources 7, pp. 326-342.

Santos Silva, J.M.C., Tenreyro, S., 2006. The Log of Gravity. The Review of Economics and Statistics, 88, 641-658.

Santos Silva, J.M.C., Tenreyro, S., 2010. On the existence of maximum likelihood estimates in Poisson regression. Economics Letters, 107, 310-312.

Schmoch, U. (2008) "Concept of a Technology classification for Country Comparisons”, Final Report to the World Intellectual Property Organisation (WIPO). Fraunhofer Institute for Systems and Innovation Research, Karlsruhe http://www.wipo.int/ipstats/en/statistics/patents/pdf/wipo_ipc_technology.pdf

Simonen J, McCann P (2008) Firm innovation: The influence of R\&D cooperation and the geography of human capital inputs. Journal of Urban Economics 64(1): 146-154

Singh J (2005) Collaborative Networks as Determinants of Knowledge Diffusion Patterns, Management Science 51: 56-70

Singh. J. and Agrawal, A.K. (2011) Recruiting for Ideas: How Firms Exploit the Prior Inventions of New Hires, Management Science 57(1), pp. 129-150.

Song, J., Almeida, P. and Wu G. (2003) Learning-by-hiring: When is mobility more to facilitate interfirm knowledge transfer?, Management Science 49, pp. 351-365.

Stephan, P. (1996) The economics of Science, Journal of Economic Literature 34(3), pp. 1199-1235.

Storper, M. and Venables, A. (2004) Buzz: face-to-face contact and the urban economy. Journal of Economic Geography 4(4): 351-370.

Ter Wal, A.L.J. (2011) "The Dynamics of the Inventor Network in German Biotechnology: Geographical Proximity versus Triadic Closure" Papers in Evolutionary Economic Geography (PEEG) 1102, Utrecht University, Section of Economic Geography.

Trippl, M. and Maier, G. (2010) Knowledge spillover agents and regional development. Papers in Regional Science 89(2): 229-233.

Verspagen, B. and Schoenmakers, W. (2004) The spatial dimension of patenting by multinational firms in Europe. Journal of Economic Geography 4(1): 23-42.

Vuong, Q.H. (1989) Likelihood ratio tests for model selection and non-nested hypothesis, Econometrica 57, pp. 307-333.

Zucker, L.G., Darby, M.R. and Armstrong, J. (1998) Geographically Localized Knowledge: Spillovers or Markets? Economic Inquiry 36(1): 65-86. 
Table 1. Summary statistics knowledge production function

\begin{tabular}{lccccc}
\hline & Obs. & Mean & St.Dev. & Min. & Max. \\
\hline $\ln ($ PAT)p.c. & 1,614 & 3.61 & 1.91 & -3.93 & 6.77 \\
$\ln ($ R\&D)p.c. & 1,614 & -1.79 & 1.53 & -6.55 & 1.06 \\
$\operatorname{lnHK}$ & 1,614 & -9.31 & 0.50 & -11.83 & -8.29 \\
W $^{\text {colls* }}$ InStockR\&D & 1,614 & 8.39 & 1.70 & 0.00 & 10.31 \\
W $^{\text {mob } * \ln S t o c k R \& D}$ & 1,614 & 7.05 & 3.57 & 0.00 & 10.63 \\
$\ln ($ population density) & 1,614 & 4.93 & 1.20 & 1.12 & 9.12 \\
Special. Index & 1,614 & 6.06 & 2.95 & 2.06 & 21.14 \\
Concen. Index & 1,614 & 0.10 & 0.12 & 0.00 & 1.00 \\
\hline
\end{tabular}

Note: The 1,614 observations correspond to 269 regions over 6 periods.

Table 2. Summary statistics, mobility. 3-year time windows: 1996-2001

\begin{tabular}{lccccc}
\hline All links & Obs. & Mean & St.Dev. & Min. & Max. \\
\hline Mobility1996 & 72,092 & 0.11 & 1.20 & 0 & 59 \\
Mobility1997 & 72,092 & 0.12 & 1.37 & 0 & 79 \\
Mobility1998 & 72,092 & 0.14 & 1.61 & 0 & 134 \\
Mobility1999 & 72,092 & 0.15 & 1.92 & 0 & 207 \\
Mobility2000 & 72,092 & 0.16 & 2.27 & 0 & 254 \\
Mobility2001 & 72,092 & 0.16 & 2.61 & 0 & 275 \\
\hline Positive links & Obs. & Mean & St.Dev. & Min. & Max. \\
\hline Mobility1996 & 2,319 & 3.28 & 5.84 & 1 & 59 \\
Mobility1997 & 2,588 & 3.37 & 6.43 & 1 & 79 \\
Mobility1998 & 2,817 & 3.53 & 7.40 & 1 & 134 \\
Mobility1999 & 2,899 & 3.67 & 8.89 & 1 & 207 \\
Mobility2000 & 2,948 & 3.83 & 10.60 & 1 & 254 \\
Mobility2001 & 2,903 & 3.89 & 12.42 & 1 & 275 \\
\hline
\end{tabular}

Note: The variables on mobility and collaborations are build summing up within time windows of three years. Thus, for instance, mobility1996 corresponds to all the movements observed in 1996, 1997 and 1998.

Table 3. Summary statistics, collaborations. 3-year time windows: 1996-2001

\begin{tabular}{lccccc}
\hline All links & Obs. & Mean & St.Dev. & Min. & Max. \\
\hline Collab.1996 & 36,046 & 1.34 & 15.37 & 0 & 1,355 \\
Collab.1997 & 36,046 & 1.54 & 16.73 & 0 & 1,449 \\
Collab.1998 & 36,046 & 1.76 & 18.80 & 0 & 1,622 \\
Collab.1999 & 36,046 & 1.91 & 20.11 & 0 & 1,701 \\
Collab.2000 & 36,046 & 2.01 & 21.31 & 0 & 1,711 \\
Collab.2001 & 36,046 & 2.03 & 21.35 & 0 & 1,642 \\
\hline Positive links & Obs. & Mean & St.Dev. & Min. & Max. \\
\hline Collab.1996 & 5,291 & 9.159 & 39.228 & 1 & 1,355 \\
Collab.1997 & 5,638 & 9.818 & 41.326 & 1 & 1,449 \\
Collab.1998 & 6,074 & 10.445 & 44.79 & 1 & 1,622 \\
Collab.1999 & 6,399 & 10.78 & 46.718 & 1 & 1,701 \\
Collab.2000 & 6,678 & 10.848 & 48.54 & 1 & 1,711 \\
Collab.2001 & 6,755 & 10.808 & 48.34 & 1 & 1,642 \\
\hline No: The & 6anis
\end{tabular}

Note: The variables on mobility and collaborations are build summing up within time windows of three years. Thus, for instance, mobility1996 corresponds to all the movements observed in 1996, 1997 and 1998.

Table 4. Correlation matrix, knowledge production function

\begin{tabular}{|c|c|c|c|c|c|c|c|c|}
\hline & 1 & 2 & 3 & 4 & 5 & 6 & 7 & 8 \\
\hline 1. $\ln$ (РAT)p.c. & 1 & & & & & & & \\
\hline 2. $\ln (R \& D)$ p.c. & 0.90 & 1 & & & & & & \\
\hline 3. $\operatorname{lnHK}$ & 0.52 & 0.56 & 1 & & & & & \\
\hline 4. $\mathrm{W}^{\text {colls } *} \ln S t o c k R \& D$ & 0.55 & 0.54 & 0.26 & 1 & & & & \\
\hline 5. $\mathrm{W}^{\mathrm{mob}} * \ln S t o c k R \& \mathrm{D}$ & 0.78 & 0.73 & 0.40 & 0.51 & 1 & & & \\
\hline 6. $\ln$ (population density) & 0.26 & 0.29 & 0.19 & 0.09 & 0.23 & 1 & & \\
\hline 7. Special. Index & -0.75 & -0.72 & -0.40 & -0.51 & -0.73 & -0.34 & 1 & \\
\hline 8. Concen. Index & -0.51 & -0.49 & -0.28 & -0.55 & -0.49 & -0.22 & 0.66 & 1 \\
\hline
\end{tabular}


Table 5. Gravity estimations - mobility (2001-2003), various techniques.

\begin{tabular}{|c|c|c|c|c|c|}
\hline & (i) & (ii) & (iii) & (iv) & (v) \\
\hline & $\begin{array}{c}\text { OLS } \\
\ln \left(M_{i j}+1\right)\end{array}$ & ppml & nbpml & zippml & zinbpml \\
\hline Ln(Geographic distance) & $\begin{array}{l}-0.003 \\
(0.002)\end{array}$ & $\begin{array}{c}-0.975^{* * *} \\
(0.134)\end{array}$ & $\begin{array}{c}-0.916^{* * *} \\
(0.049)\end{array}$ & $\begin{array}{c}-0.690^{* * *} \\
(0.120)\end{array}$ & $\begin{array}{c}-0.704^{* * *} \\
(0.055)\end{array}$ \\
\hline Contiguity dummy & $\begin{array}{c}0.488 * * * \\
(0.027)\end{array}$ & $\begin{array}{c}0.774 * * * \\
(0.133)\end{array}$ & $\begin{array}{c}1.075^{* * *} \\
(0.077)\end{array}$ & $\begin{array}{c}0.885^{* * *} \\
(0.121)\end{array}$ & $\begin{array}{c}1.208 * * * \\
(0.076)\end{array}$ \\
\hline Ln(Cognitive distance) & $\begin{array}{c}-0.063^{* * *} \\
(0.004)\end{array}$ & $\begin{array}{c}-0.331^{* * *} \\
(0.096)\end{array}$ & $\begin{array}{c}-0.404^{* * *} \\
(0.052)\end{array}$ & $\begin{array}{c}-0.224^{* * * *} \\
(0.087)\end{array}$ & $\begin{array}{c}-0.263^{* * *} \\
(0.057)\end{array}$ \\
\hline Same country dummy & $\begin{array}{c}0.307 * * * \\
(0.009)\end{array}$ & $\begin{array}{c}1.713^{* * *} \\
(0.156)\end{array}$ & $\begin{array}{c}2.176^{* * * *} \\
(0.062)\end{array}$ & $\begin{array}{c}0.780^{* * *} \\
(0.150)\end{array}$ & $\begin{array}{c}1.417 * * * \\
(0.079)\end{array}$ \\
\hline Constant & $\begin{array}{c}-0.139 * * * \\
(0.024)\end{array}$ & $\begin{array}{c}0.524 \\
(1.437)\end{array}$ & $\begin{array}{l}-0.329 \\
(0.872)\end{array}$ & $\begin{array}{l}-0.072 \\
(1.298)\end{array}$ & $\begin{array}{l}-0.761 \\
(0.910)\end{array}$ \\
\hline Origin F.E. & yes & $\begin{array}{l}\text { yes } \\
\text { ves }\end{array}$ & yes & yes & $\begin{array}{l}\text { yes } \\
\text { ves }\end{array}$ \\
\hline $\begin{array}{l}\text { Destination F.E. } \\
\text { Overdispersion }\end{array}$ & yes & yes & $\begin{array}{c}\text { yes } \\
0.270^{* * *} \\
(0.068)\end{array}$ & yes & $\begin{array}{c}\text { yes } \\
-0.221^{* * *} \\
(0.052)\end{array}$ \\
\hline $\begin{array}{l}\text { LR of } \alpha=0 \\
\text { p-value }\end{array}$ & & & & & $\begin{array}{c}4466.65^{* * * *} \\
0.000\end{array}$ \\
\hline Vuong & & & & $5.97 * * *$ & $6.90 * * *$ \\
\hline $\begin{array}{l}\text { p-value } \\
\text { Observations }\end{array}$ & 72,088 & 50,401 & 50,401 & $\begin{array}{c}0.000 \\
50,401\end{array}$ & $\begin{array}{c}0.000 \\
50,401\end{array}$ \\
\hline Adjusted R2 & 0.309 & & & & \\
\hline $\mathrm{BIC}$ & $-8,076.42$ & $33,495.29$ & $25,850.41$ & $29,990.54$ & $25,534.72$ \\
\hline AIC & $-13,045.85$ & $29,496.31$ & $21,842.60$ & $25,947.43$ & $21,482.78$ \\
\hline Log-likelihood & $7,063.92$ & $-14,295.15$ & $-10,467.30$ & $-12,515.71$ & $-10,282.39$ \\
\hline McFadden djusted-R2 & 0.309 & 0.694 & 0.343 & 0.519 & 0.354 \\
\hline
\end{tabular}

Robust standard errors in parentheses. ${ }^{* * *} \mathrm{p}<0.01,{ }^{* *} \mathrm{p}<0.05,{ }^{*} \mathrm{p}<0.1$. Overdispersion tests largely reject the null hypothesis of no overdispersion. Vuong statistics (Vuong, 1989), are also performed and reported at the bottom of each regression. The tests performed point to the need of the zero-inflated models to accommodate our estimations to the excess of zeros. 'ppml' stands for poisson pseudo-maximum likelihood; 'nbpml' stands for negative binomial pseudo-maximum likelihood; 'zippml' stands for zero-inflated Poisson pseudo-maximum likelihood; and 'zinbpml' stands for zero-inflated negative binomial pseudo-maximum likelihood. Due to the inclusion of fixed effects, pseudomaximum likelihood estimations do not converge unless we drop the regional fixed-effects (and their corresponding observations) for which the region has zero recorded inventors' flows to every other region in the sample. This explains the smaller number of observations used in these estimations (see Santos Silva and Tenreyro, 2010). For the case of 'zippml' and 'zinbpml', the logit part is not shown here but can be provided upon request. In these cases, the variables chosen as regressors in the binary part are the same as those of the count data part. In principle, there is no formal restriction to including the same regressors in both processes, aside from possible theoretical concerns. 
Table 6. Gravity estimations - collaborations (2001-2003), various techniques.

\begin{tabular}{|c|c|c|c|c|c|}
\hline & (i) & (ii) & (iii) & (iv) & (v) \\
\hline & $\begin{array}{c}\text { OLS } \\
\ln \left(N_{i j}+1\right)\end{array}$ & ppml & nbpml & zippml & zinbpml \\
\hline Ln(Geographic distance) & $\begin{array}{c}-0.116^{* * * *} \\
(0.007)\end{array}$ & $\begin{array}{c}-0.902^{* * *} \\
(0.044)\end{array}$ & $\begin{array}{c}-0.815^{* * *} \\
(0.028)\end{array}$ & $\begin{array}{c}-0.837 * * * \\
(0.046)\end{array}$ & $\begin{array}{c}-0.762 * * * \\
(0.034)\end{array}$ \\
\hline Contiguity Dummy & $\begin{array}{c}0.856 * * * \\
(0.057)\end{array}$ & $\begin{array}{c}0.869 * * * \\
(0.061)\end{array}$ & $\begin{array}{c}1.022 * * * \\
(0.061)\end{array}$ & $\begin{array}{c}0.925^{* * *} \\
(0.061)\end{array}$ & $\begin{array}{c}1.029 * * * \\
(0.059)\end{array}$ \\
\hline Ln(Cognitive distance) & $\begin{array}{c}-0.194^{* * *} \\
(0.010)\end{array}$ & $\begin{array}{c}-0.197 * * * \\
(0.049)\end{array}$ & $\begin{array}{c}-0.363^{* * *} \\
(0.034)\end{array}$ & $\begin{array}{c}-0.165^{* * *} \\
(0.052)\end{array}$ & $\begin{array}{c}-0.222^{* * *} \\
(0.035)\end{array}$ \\
\hline Same country dummy & $\begin{array}{c}1.188 * * * \\
(0.023)\end{array}$ & $\begin{array}{c}1.666 * * * \\
(0.079)\end{array}$ & $\begin{array}{c}2.097 * * * \\
(0.045)\end{array}$ & $\begin{array}{c}1.403^{* * *} \\
(0.080)\end{array}$ & $\begin{array}{c}1.930 * * * \\
(0.049)\end{array}$ \\
\hline Constant & $\begin{array}{c}0.329 * * * \\
(0.079)\end{array}$ & $\begin{array}{c}1.723 * * * \\
(0.598)\end{array}$ & $\begin{array}{c}0.531 \\
(0.523)\end{array}$ & $\begin{array}{c}1.754 * * * \\
(0.599)\end{array}$ & $\begin{array}{c}0.553 \\
(0.533)\end{array}$ \\
\hline Origin F.E. & $\begin{array}{l}\text { yes } \\
\text { ves }\end{array}$ & $\begin{array}{l}\text { yes } \\
\text { ves }\end{array}$ & $\begin{array}{l}\text { yes } \\
\text { ves }\end{array}$ & $\begin{array}{l}\text { yes } \\
\text { ves }\end{array}$ & $\begin{array}{l}\text { yes } \\
\text { ves }\end{array}$ \\
\hline Overdispersion & & & $\begin{array}{c}-0.313^{* * *} \\
(0.041)\end{array}$ & & $\begin{array}{c}\text { yes } \\
-0.601^{* * *} \\
(0.048)\end{array}$ \\
\hline LR of $\alpha=0$ & & & & 12.33 & 1200 \\
\hline p-value & & & & 0.000 & 0.000 \\
\hline Vuong & & & & & 6.21 \\
\hline p-value & & & & & 0.000 \\
\hline Observations & 36,044 & 33,674 & 33,674 & 33,674 & 33,674 \\
\hline Adjusted-R2 & 0.608 & & & & \\
\hline $\mathrm{BIC}$ & $52,528.863$ & $66,509.488$ & $52,004.326$ & 63,699.906 & $51,837.742$ \\
\hline AIC & $47,934.423$ & $62,103.485$ & $47,589.898$ & $59,251.779$ & $47,381.192$ \\
\hline Log-likelihood & $-23,426.211$ & $-30,528.742$ & $-23,270.949$ & $-29,097.890$ & $-23,161.596$ \\
\hline McFadden djusted-R2 & 0.602 & 0.875 & 0.327 & 0.800 & 0.329 \\
\hline
\end{tabular}

Robust standard errors in parentheses. ${ }^{* * *} \mathrm{p}<0.01,{ }^{* *} \mathrm{p}<0.05, * \mathrm{p}<0.1$. Overdispersion tests largely reject the null hypothesis of no overdispersion. Vuong statistics (Vuong, 1989), are also performed and reported at the bottom of each regression. The tests performed point to the need of the zero-inflated models to accommodate our estimations to the excess of zeros. 'ppml' stands for poisson pseudo-maximum likelihood; 'nbpml' stands for negative binomial pseudo-maximum likelihood; 'zippml' stands for zero-inflated Poisson pseudo-maximum likelihood; and 'zinbpml' stands for zero-inflated negative binomial pseudo-maximum likelihood. Due to the inclusion of fixed effects, pseudomaximum likelihood estimations do not converge unless we drop the regional fixed-effects (and their corresponding observations) for which the region has zero recorded inventors' flows to every other region in the sample. This explains the smaller number of observations used in these estimations (see Santos Silva and Tenreyro, 2010). For the case of 'zippml' and 'zinbpml', the logit part is not shown here but can be provided upon request. In these cases, the variables chosen as regressors in the binary part are the same as those of the count data part. In principle, there is no formal restriction to including the same regressors in both processes, aside from possible theoretical concerns. 
Table 7. Gravity estimations - mobility. Zero-inflated negative binomial, 19962001

\begin{tabular}{|c|c|c|c|c|c|c|}
\hline & (i) & (ii) & (iii) & (iv) & (v) & (vi) \\
\hline & 1996 & 1997 & 1998 & 1999 & 2000 & 2001 \\
\hline $\begin{array}{l}\text { Ln(Geographic } \\
\text { distance) }\end{array}$ & $-0.654 * * *$ & $-0.702 * * *$ & $-0.758 * * *$ & $-0.733 * * *$ & $-0.738 * * *$ & $-0.704 * * *$ \\
\hline & $(0.055)$ & $(0.056)$ & $(0.055)$ & $(0.056)$ & $(0.056)$ & $(0.055)$ \\
\hline Contiguity Dummy & $\begin{array}{c}1.253^{* * *} \\
(0.081)\end{array}$ & $\begin{array}{c}1.187 * * * \\
(0.077)\end{array}$ & $\begin{array}{c}1.114 * * * \\
(0.073)\end{array}$ & $\begin{array}{c}1.159 * * * \\
(0.072)\end{array}$ & $\begin{array}{c}1.159 * * * \\
(0.075)\end{array}$ & $\begin{array}{c}1.208 * * * \\
(0.076)\end{array}$ \\
\hline Ln(Cognitive distance) & $\begin{array}{c}-0.308 * * * \\
(0.068)\end{array}$ & $\begin{array}{c}-0.234^{* * *} \\
(0.069)\end{array}$ & $\begin{array}{c}-0.143 * * \\
(0.063)\end{array}$ & $\begin{array}{c}-0.116^{* *} \\
(0.057)\end{array}$ & $\begin{array}{c}-0.181^{* * * *} \\
(0.057)\end{array}$ & $\begin{array}{c}-0.263 * * * \\
(0.057)\end{array}$ \\
\hline Same country dummy & $\begin{array}{c}1.579 * * * \\
(0.096)\end{array}$ & $\begin{array}{c}1.558 * * * \\
(0.094)\end{array}$ & $\begin{array}{c}1.524^{* * *} \\
(0.087)\end{array}$ & $\begin{array}{c}1.458 * * * \\
(0.079)\end{array}$ & $\begin{array}{c}1.435^{* * *} \\
(0.077)\end{array}$ & $\begin{array}{c}1.417 * * * \\
(0.079)\end{array}$ \\
\hline Constant & $\begin{array}{l}-1.137 \\
(0.800)\end{array}$ & $\begin{array}{l}-1.043 \\
(0.862)\end{array}$ & $\begin{array}{l}-0.853 \\
(0.920)\end{array}$ & $\begin{array}{l}-0.248 \\
(0.795)\end{array}$ & $\begin{array}{c}-0.632 \\
(0.858)\end{array}$ & $\begin{array}{c}-0.761 \\
(0.910)\end{array}$ \\
\hline Origin F.E. & yes & yes & yes & yes & yes & yes \\
\hline Destination F.E. & yes & yes & yes & yes & yes & yes \\
\hline LR of $\alpha=0$ & $1,783.67$ & $2,082.29$ & $2,236.44$ & $2,647.52$ & $3,608.57$ & $4,466.65$ \\
\hline p-value & 0.000 & 0.000 & 0.000 & 0.000 & 0.000 & 0.000 \\
\hline Vuong & 6.45 & 6.31 & 6.47 & 7.22 & 7.05 & 6.90 \\
\hline p-value & 0.000 & 0.000 & 0.000 & 0.000 & 0.000 & 0.000 \\
\hline Observations & 43,062 & 44,321 & 45,591 & 46,879 & 47,966 & 50,401 \\
\hline Non-zero obs. & 2,319 & 2,588 & 2,817 & 2,899 & 2,948 & 2,903 \\
\hline $\mathrm{BIC}$ & $20,704.10$ & $22,506.88$ & $24,174.98$ & $24,845.37$ & $25,553.64$ & $25,534.72$ \\
\hline AIC & $17,019.18$ & $18,757.52$ & $20,361.08$ & $20,966.76$ & $21,620.99$ & $21,482.78$ \\
\hline Log-likelihood & $-8,084.59$ & $-8,947.76$ & $-9,743.54$ & $-10,040.38$ & $-10,362.49$ & $-10,282.39$ \\
\hline Adjusted-R2 & 0.356 & 0.357 & 0.356 & 0.358 & 0.353 & 0.354 \\
\hline
\end{tabular}


Table 8. Gravity estimations - collaborations. Zero-inflated negative binomial, 1996-2001

\begin{tabular}{|c|c|c|c|c|c|c|}
\hline & (i) & (ii) & (iii) & (iv) & (v) & (vi) \\
\hline & 1996 & 1997 & 1998 & 1999 & 2000 & 2001 \\
\hline $\begin{array}{l}\text { Ln(Geographic } \\
\text { distance) }\end{array}$ & $-0.677 * * *$ & $-0.657 * * *$ & $-0.683 * * *$ & $-0.696 * * *$ & $-0.724 * * *$ & $-0.762 * * *$ \\
\hline & $(0.033)$ & $(0.033)$ & $(0.034)$ & $(0.033)$ & $(0.034)$ & $(0.034)$ \\
\hline Contiguity Dummy & $\begin{array}{c}1.043^{* * *} \\
(0.058)\end{array}$ & $\begin{array}{c}1.065^{* * *} \\
(0.058)\end{array}$ & $\begin{array}{c}1.071^{* * *} \\
(0.056)\end{array}$ & $\begin{array}{c}1.067 * * * \\
(0.057)\end{array}$ & $\begin{array}{c}1.063 * * * \\
(0.057)\end{array}$ & $\begin{array}{c}1.029 * * * \\
(0.059)\end{array}$ \\
\hline Ln(Cognitive distance) & $\begin{array}{c}-0.264^{* * *} \\
(0.041)\end{array}$ & $\begin{array}{c}-0.227 * * * \\
(0.039)\end{array}$ & $\begin{array}{c}-0.247^{* * *} \\
(0.037)\end{array}$ & $\begin{array}{c}-0.267 * * * \\
(0.038)\end{array}$ & $\begin{array}{c}-0.243^{* * *} \\
(0.036)\end{array}$ & $\begin{array}{c}-0.222 * * * \\
(0.035)\end{array}$ \\
\hline Same country dummy & $\begin{array}{c}2.119 * * * \\
(0.052)\end{array}$ & $\begin{array}{c}2.144^{* * *} \\
(0.051)\end{array}$ & $\begin{array}{c}2.032^{* * *} \\
(0.049)\end{array}$ & $\begin{array}{c}2.024^{* * *} \\
(0.049)\end{array}$ & $\begin{array}{c}1.929 * * * \\
(0.048)\end{array}$ & $\begin{array}{c}1.930 * * * \\
(0.049)\end{array}$ \\
\hline Constant & $\begin{array}{c}1.133 \\
(0.771)\end{array}$ & $\begin{array}{c}1.011 \\
(0.790)\end{array}$ & $\begin{array}{c}0.777 \\
(0.609)\end{array}$ & $\begin{array}{c}0.476 \\
(0.521)\end{array}$ & $\begin{array}{l}0.879 * \\
(0.519)\end{array}$ & $\begin{array}{c}0.553 \\
(0.533)\end{array}$ \\
\hline Origin F.E. & yes & yes & yes & yes & yes & yes \\
\hline Destination F.E. & yes & yes & yes & yes & yes & yes \\
\hline Overdispersion & $7,332.72$ & $8,301.07$ & $9,695.56$ & 12,000 & 12,000 & 12,000 \\
\hline p-value & 0.000 & 0.000 & 0.000 & 0.000 & 0.000 & 0.000 \\
\hline Vuong & 6.51 & 7.09 & 7.41 & 6.66 & 6.75 & 6.21 \\
\hline p-value & 0.000 & 0.000 & 0.000 & 0.000 & 0.000 & 0.000 \\
\hline Observations & 30,034 & 30,043 & 30,281 & 32,003 & 32,902 & 33,674 \\
\hline Non-zero obs. & 5,291 & 5,638 & 6,074 & 6,399 & 6,678 & 6,754 \\
\hline BIC & $40,702.82$ & $43,446.34$ & $46,850.60$ & $49,120.99$ & $51,391.51$ & $51,837.74$ \\
\hline AIC & $36,547.78$ & $39,291.15$ & $42,674.83$ & $44,800.22$ & $46,997.64$ & $47,381.19$ \\
\hline Log-likelihood & $-17,773.89$ & $-19,145.57$ & $-20,835.41$ & $-21,884.11$ & $-22,975.82$ & $-23,161.59$ \\
\hline Adjusted-R2 & 0.342 & 0.335 & 0.327 & 0.331 & 0.327 & 0.329 \\
\hline
\end{tabular}

Robust standard errors in parentheses. ${ }^{* * *} \mathrm{p}<0.01,{ }^{* *} \mathrm{p}<0.05,{ }^{*} \mathrm{p}<0.1$. Overdispersion tests largely reject the null hypothesis of no overdispersion. Vuong statistics (Vuong, 1989), are also performed and reported at the bottom of each regression. The tests performed point to the need of the zero-inflated models to accommodate our estimations to the excess of zeros. In these cases, the variables chosen as regressors in the binary part are the same as those of the count data part. In principle, there is no formal restriction to including the same regressors in both processes, aside from possible theoretical concerns. 
Table 9. Main estimation results. Dep. Var.: InPATpc, KPF 1999-2004

\begin{tabular}{|c|c|c|c|c|c|c|}
\hline & (i) & (ii) & (iii) & (iv) & (v) & (vi) \\
\hline & Pooled OLS & $\mathrm{RE}$ & FE & Pooled OLS & RE & FE \\
\hline $\ln (\mathrm{R} \& \mathrm{D})$ p.c. & $\begin{array}{c}0.838 * * * \\
(0.021)\end{array}$ & $\begin{array}{c}0.744 * * * \\
(0.027)\end{array}$ & $\begin{array}{c}0.204^{* * *} \\
(0.038)\end{array}$ & $\begin{array}{c}0.805^{* * *} \\
(0.022)\end{array}$ & $\begin{array}{c}0.737 * * * \\
(0.028)\end{array}$ & $\begin{array}{c}0.210^{* * *} \\
(0.038)\end{array}$ \\
\hline $\operatorname{lnHK}$ & $\begin{array}{c}0.120 * * * \\
(0.045)\end{array}$ & $\begin{array}{c}0.115^{* * * *} \\
(0.038)\end{array}$ & $\begin{array}{c}0.187 * * * \\
(0.036)\end{array}$ & $\begin{array}{c}0.171^{* * *} \\
(0.044)\end{array}$ & $\begin{array}{c}0.116^{* * * *} \\
(0.038)\end{array}$ & $\begin{array}{c}0.188^{* * *} \\
(0.036)\end{array}$ \\
\hline $\mathrm{W}^{\mathrm{mob}} * \ln S t o c k R \& D$ & $\begin{array}{c}0.133 * * * \\
(0.008)\end{array}$ & $\begin{array}{c}0.023 * * * \\
(0.005)\end{array}$ & $\begin{array}{l}0.011^{* *} \\
(0.005)\end{array}$ & $\begin{array}{c}0.105^{* * *} \\
(0.008)\end{array}$ & $\begin{array}{c}0.023 * * * \\
(0.005)\end{array}$ & $\begin{array}{c}0.012 * * * \\
(0.005)\end{array}$ \\
\hline $\mathrm{W}^{\mathrm{colls}} * \ln S t o c k R \& D$ & $\begin{array}{c}0.058 * * * \\
(0.013)\end{array}$ & $\begin{array}{c}0.043^{* * *} \\
(0.007)\end{array}$ & $\begin{array}{c}0.039 * * * \\
(0.007)\end{array}$ & $\begin{array}{c}0.046^{* * *} \\
(0.014)\end{array}$ & $\begin{array}{c}0.040^{* * *} \\
(0.008)\end{array}$ & $\begin{array}{c}0.037 * * * \\
(0.007)\end{array}$ \\
\hline $\ln$ (population density) & & & & $\begin{array}{c}0.373 * * * \\
(0.073)\end{array}$ & $\begin{array}{l}0.335^{*} \\
(0.177)\end{array}$ & $\begin{array}{l}4.943 * * \\
(2.307)\end{array}$ \\
\hline $\ln \left(\right.$ population density) ${ }^{\wedge}$ & & & & $\begin{array}{c}-0.040 * * * \\
(0.007)\end{array}$ & $\begin{array}{l}-0.022 \\
(0.017)\end{array}$ & $\begin{array}{l}-0.438^{*} \\
(0.229)\end{array}$ \\
\hline Special. Index & & & & $\begin{array}{c}-0.079 * * * \\
(0.011)\end{array}$ & $\begin{array}{c}0.003 \\
(0.009)\end{array}$ & $\begin{array}{c}0.031^{* * *} \\
(0.008)\end{array}$ \\
\hline Concen. Index & & & & $\begin{array}{c}0.253 \\
(0.222)\end{array}$ & $\begin{array}{l}-0.172 \\
(0.114)\end{array}$ & $\begin{array}{c}-0.360 * * * \\
(0.102)\end{array}$ \\
\hline Constant & $\begin{array}{c}4.798 * * * \\
(0.416)\end{array}$ & $\begin{array}{c}5.488 * * * \\
(0.368)\end{array}$ & $\begin{array}{c}5.320^{* * * *} \\
(0.343)\end{array}$ & $\begin{array}{c}5.159 * * * \\
(0.440)\end{array}$ & $\begin{array}{c}4.430 * * * \\
(0.569)\end{array}$ & $\begin{array}{l}-7.903 \\
(5.837)\end{array}$ \\
\hline Hausman test & \multicolumn{4}{|c|}{$413.07 * * *$} & \multicolumn{2}{|c|}{$444.62 * * *$} \\
\hline AIC & $3,628.26$ & & -177.098 & 3,539.652 & & -197.111 \\
\hline BIC & $3,655.192$ & & -150.1656 & $3,588.13$ & & -148.6328 \\
\hline Observations & 1,614 & 1,614 & 1,614 & 1,614 & 1,614 & 1,614 \\
\hline Adjusted R2 & 0.848 & & & 0.856 & & \\
\hline R2 within & & 0.0788 & 0.0996 & & 0.0816 & 0.1151 \\
\hline R2 between & & 0.8503 & 0.8415 & & 0.8461 & 0.0896 \\
\hline R2 overall & & 0.8320 & 0.8158 & & 0.8284 & 0.0894 \\
\hline Number of periods & 6 & 6 & 6 & 6 & 6 & 6 \\
\hline Number of regions & 269 & 269 & 269 & 269 & 269 & 269 \\
\hline
\end{tabular}


Table 10. Robustness checks. Dep. Var.: InPATpc

\begin{tabular}{|c|c|c|c|c|c|}
\hline & (i) & (ii) & (iii) & (iv) & (v) \\
\hline & zippml & Actual values & $\begin{array}{l}\text { Spatial } \\
\text { R\&D }\end{array}$ & $\begin{array}{c}\text { Spatial } \\
\text { R\&D }\end{array}$ & $\begin{array}{c}\text { Stock } \\
\text { R\&Dpc }\end{array}$ \\
\hline & FE & FE & FE & FE & $\mathrm{FE}$ \\
\hline $\ln (\mathrm{R} \& \mathrm{D})$ p.c. & $\begin{array}{c}0.210 * * * \\
(0.038)\end{array}$ & $\begin{array}{c}0.206 * * * \\
(0.038)\end{array}$ & $\begin{array}{c}0.090 * * \\
(0.039)\end{array}$ & $\begin{array}{c}0.090 * * \\
(0.039)\end{array}$ & $\begin{array}{c}0.398 * * * \\
(0.045)\end{array}$ \\
\hline $\operatorname{lnHK}$ & $\begin{array}{c}0.190 * * * \\
(0.036)\end{array}$ & $\begin{array}{c}0.191^{* * *} \\
(0.036)\end{array}$ & $\begin{array}{c}0.071^{*} \\
(0.038)\end{array}$ & $\begin{array}{c}0.062 \\
(0.038)\end{array}$ & $\begin{array}{c}0.108^{* * *} * \\
(0.038)\end{array}$ \\
\hline $\mathrm{W}^{\mathrm{mob}} * \ln S t o c k R \& \mathrm{D}$ & $\begin{array}{c}0.012^{* * *} \\
(0.005)\end{array}$ & $\begin{array}{c}0.014^{* * *} \\
(0.004)\end{array}$ & & $\begin{array}{c}0.009 * * \\
(0.004)\end{array}$ & $\begin{array}{l}0.008^{*} \\
(0.005)\end{array}$ \\
\hline $\mathrm{W}^{\text {colls } * \ln S t o c k R \& D}$ & $\begin{array}{c}0.036 * * * \\
(0.007)\end{array}$ & $\begin{array}{c}0.034 * * * \\
(0.007)\end{array}$ & & $\begin{array}{c}0.024 * * * \\
(0.007)\end{array}$ & $\begin{array}{c}0.029 * * * \\
(0.007)\end{array}$ \\
\hline $\mathrm{W}^{\mathrm{contig}} * \ln S$ tockR\&D & & & $\begin{array}{c}0.522^{* * *} \\
(0.053)\end{array}$ & $\begin{array}{c}0.470 * * * \\
(0.054)\end{array}$ & \\
\hline $\ln$ (population density) & $\begin{array}{c}4.939 * * \\
(2.310)\end{array}$ & $\begin{array}{l}4.510^{*} \\
(2.303)\end{array}$ & $\begin{array}{c}4.523^{* *} \\
(2.250)\end{array}$ & $\begin{array}{c}5.174 * * \\
(2.245)\end{array}$ & $\begin{array}{c}4.835^{* *} \\
(2.268)\end{array}$ \\
\hline $\ln ($ population density)^2 & $\begin{array}{c}-0.438^{*} \\
(0.229)\end{array}$ & $\begin{array}{l}-0.396^{*} \\
(0.229)\end{array}$ & $\begin{array}{c}-0.589 * * * \\
(0.225)\end{array}$ & $\begin{array}{c}-0.621^{* * *} \\
(0.224)\end{array}$ & $\begin{array}{c}-0.513^{* *} \\
(0.225)\end{array}$ \\
\hline Special. Index & $\begin{array}{c}0.031^{* * *} \\
(0.008)\end{array}$ & $\begin{array}{c}0.031^{* * *} \\
(0.008)\end{array}$ & $\begin{array}{c}0.037 * * * \\
(0.008)\end{array}$ & $\begin{array}{c}0.038 * * * \\
(0.008)\end{array}$ & $\begin{array}{c}0.039 * * * \\
(0.008)\end{array}$ \\
\hline Concen. Index & $\begin{array}{c}-0.366 * * * \\
(0.102)\end{array}$ & $\begin{array}{c}-0.374 * * * \\
(0.102)\end{array}$ & $\begin{array}{c}-0.440^{* * *} \\
(0.097)\end{array}$ & $\begin{array}{c}-0.368^{* * *} \\
(0.099)\end{array}$ & $\begin{array}{c}-0.396 * * * \\
(0.100)\end{array}$ \\
\hline Constant & $\begin{array}{c}-7.847 \\
(5.846)\end{array}$ & $\begin{array}{c}-6.827 \\
(5.822)\end{array}$ & $\begin{array}{c}-6.672 \\
(5.680)\end{array}$ & $\begin{array}{c}-9.060 \\
(5.681)\end{array}$ & $\begin{array}{c}-6.511 \\
(5.741)\end{array}$ \\
\hline Hausman test & $443.78 * * *$ & $447.43^{* * *}$ & $356.04 * * *$ & $351.68 * * *$ & $127.56 * * *$ \\
\hline AIC & -193.6534 & -196.5001 & -269.3157 & -284.8043 & -252.792 \\
\hline BIC & -145.1752 & -148.0218 & -226.224 & -230.9396 & -204.3137 \\
\hline Observations & 1,614 & 1,614 & 1,614 & 1,614 & 1,614 \\
\hline R2 within & 0.1132 & 0.1148 & 0.1528 & 0.1630 & 0.1451 \\
\hline R2 between & 0.0889 & 0.1063 & 0.0004 & 0.0036 & 0.0535 \\
\hline R2 overall & 0.0887 & 0.1060 & 0.0005 & 0.0038 & 0.0539 \\
\hline Number of periods & 6 & 6 & 6 & 6 & 6 \\
\hline Number of regions & 269 & 269 & 269 & 269 & 269 \\
\hline
\end{tabular}

Standard errors in parentheses ${ }^{* * *} \mathrm{p}<0.01,{ }^{* *} \mathrm{p}<0.05,{ }^{*} \mathrm{p}<0.1$ 
Figure 1. Observed versus estimated probability of the number of movements.

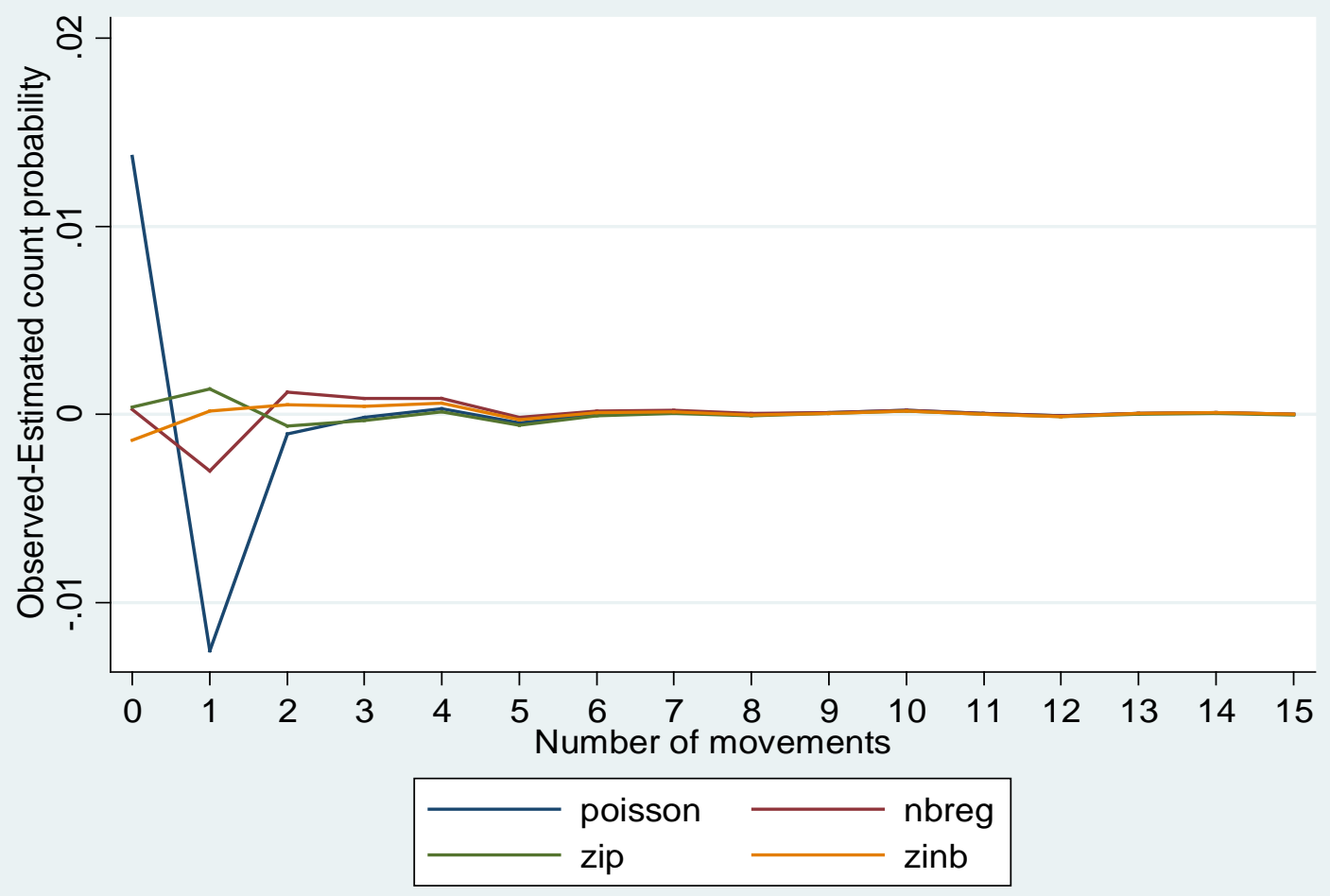

Figure 2. Observed versus estimated probability of the number of collaborations.

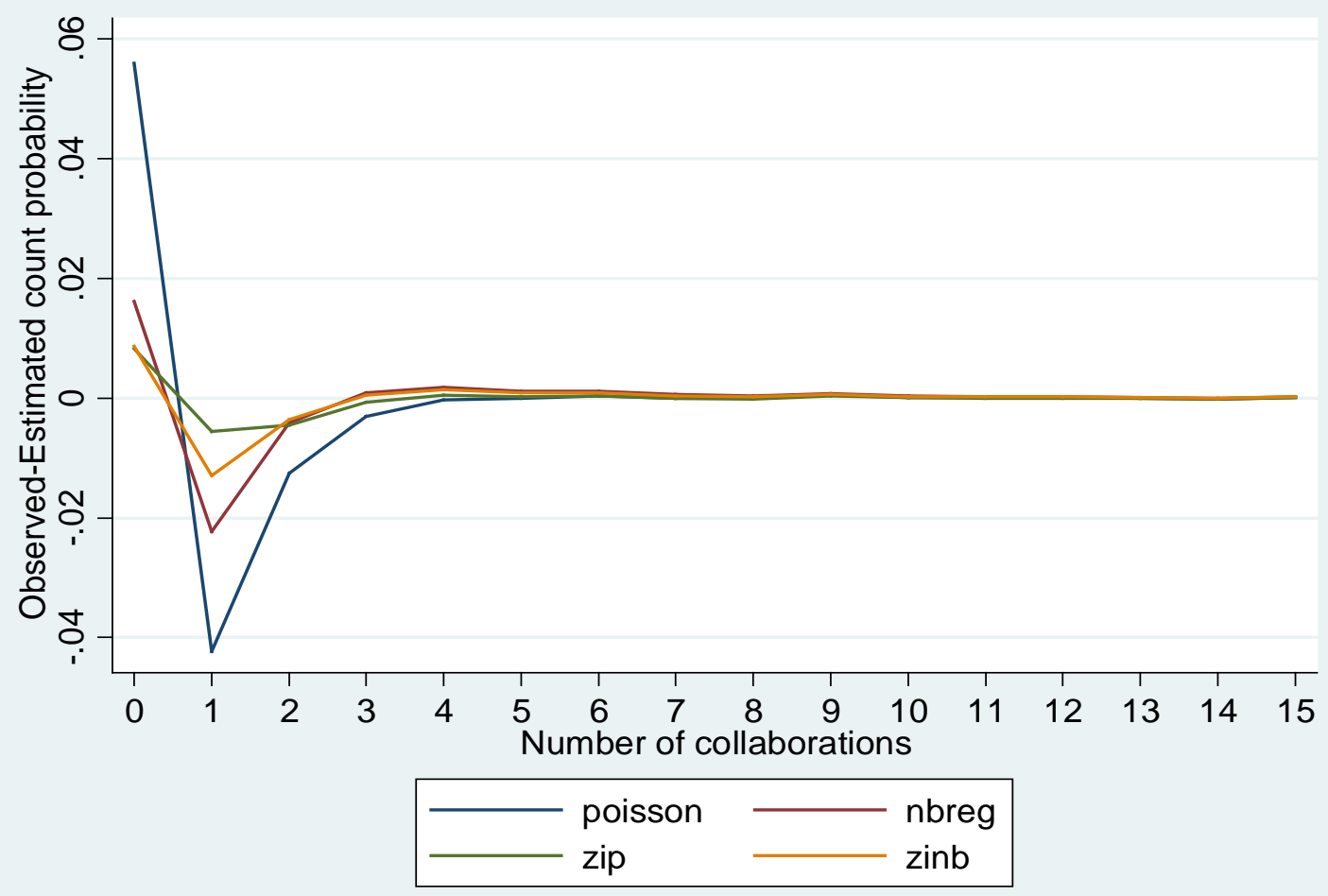




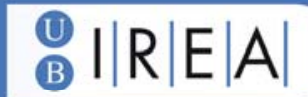

Institut de Recerca en Economia Aplicada Regional i Públic

Research Institute of Applied Economics

WEBSITE: www.ub-irea.com·CONTACT: irea@ub.edu

\section{$\mathrm{AQR}$}

Grup de Recerca Anàlisi Quantitativa Regional

Regional Quantitative Analysis Research Group

WEBSITE: www.ub.edu/aqr/•CONTACT: aqr@ub.edu 